\title{
Spore forming Actinobacterial diversity of Cholistan Desert Pakistan: Polyphasic taxonomy, antimicrobial potential and chemical profiling
}

\author{
Adeela Fatima', Usman Aftab ${ }^{1}$, Khaled A. Shaaban ${ }^{2,3}$, Jon S. Thorson ${ }^{2,3}$ and Imran Sajid ${ }^{1 *}$ (D)
}

\begin{abstract}
Background: Actinobacteria are famous for the production of unique secondary metabolites that help in controlling the continuously emerging drug resistance all over the globe. This study aimed at the investigation of an extreme environment the Cholistan desert, located in southern Punjab, Pakistan, for actinobacterial diversity and their activity against methicillin resistant Staphylococcus aureus (MRSA). The Cholistan desert is a sub-tropical and arid ecosystem with harsh environment, limited rainfall and low humidity. The 20 soil and sand samples were collected from different locations in the desert and the actinobacterial strains were selectively isolated. The isolated strains were identified using a polyphasic taxonomic approach including morphological, biochemical, physiological characterization, scanning electron microscopy (SEM) and by $16 \mathrm{~S}$ rRNA gene sequencing.

Results: A total of 110 desert actinobacterial strains were recovered, which were found to be belonging to 3 different families of the order Actinomycetales, including the family Streptomycetaceae, family Pseudonocardiaceae and the family Micrococcaceae. The most frequently isolated genus was Streptomyces along with the genera Pseudonocardia and Arthrobacter. The isolated strains exhibited promising antimicrobial activity against methicillin resistant Staphylococcus aureus (MRSA) with zone of inhibition in the range of 9-32 $\mathrm{mm}$ in antimicrobial screening assays. The chemical profiling by thin layer chromatography, HPLC-UVNis and LC-MS analysis depicted the presence of different structural classes of antibiotics.
\end{abstract}

Conclusion: The study revealed that Cholistan desert harbors immense actinobacterial diversity and most of the strains produce structurally diverse bioactive secondary metabolites, which are a promising source of novel antimicrobial drug candidates.

Keywords: Actinobacterial diversity, Cholistan desert, MRSA, Polyphasic taxonomy, Scanning electron microscopy (SEM), $16 \mathrm{~S}$ rRNA gene sequencing

\section{Background}

The actinomycetes thriving in harsh environments have the capability to endure the extreme temperature, drought conditions and to produce very unique antibacterial compounds. The desert soils are rich and untapped source of novel strains of these extraordinary species. There is a need to explore and screen these

\footnotetext{
* Correspondence: imran.mmg@pu.edu.pk

'Department of Microbiology and Molecular Genetics (MMG), University of

the Punjab, Quaid-e-Azam Campus, Lahore 54590, Pakistan

Full list of author information is available at the end of the article
}

niches for the diversity of these prolific sources of antibiotics to combat the alarming situation of antimicrobial resistance. The Cholistan desert in Pakistan is a unique and unexplored ecological system covering the expanse of $26,300 \mathrm{~km}^{2}$ in the south of district Bahawalpur in the Punjab. It extends to the Thar desert in Sindh between longitudes $69^{\circ} 52^{\prime}$ to $73^{\circ} 24^{\prime} \mathrm{E}$ and latitudes $28^{\circ} 42^{\prime}$ to $29^{\circ}$ $25^{\prime} \mathrm{N}$ (Fig. 1), present at an altitude of $89 \mathrm{~m}$ above sea level [1]. With reference to the climate, it is categorized as harsh, sub-tropical region with scarcity of precipitation and long dearth season, low relative humidity, with

(c) The Author(s). 2019 Open Access This article is distributed under the terms of the Creative Commons Attribution 4.0 International License (http://creativecommons.org/licenses/by/4.0/), which permits unrestricted use, distribution, and 


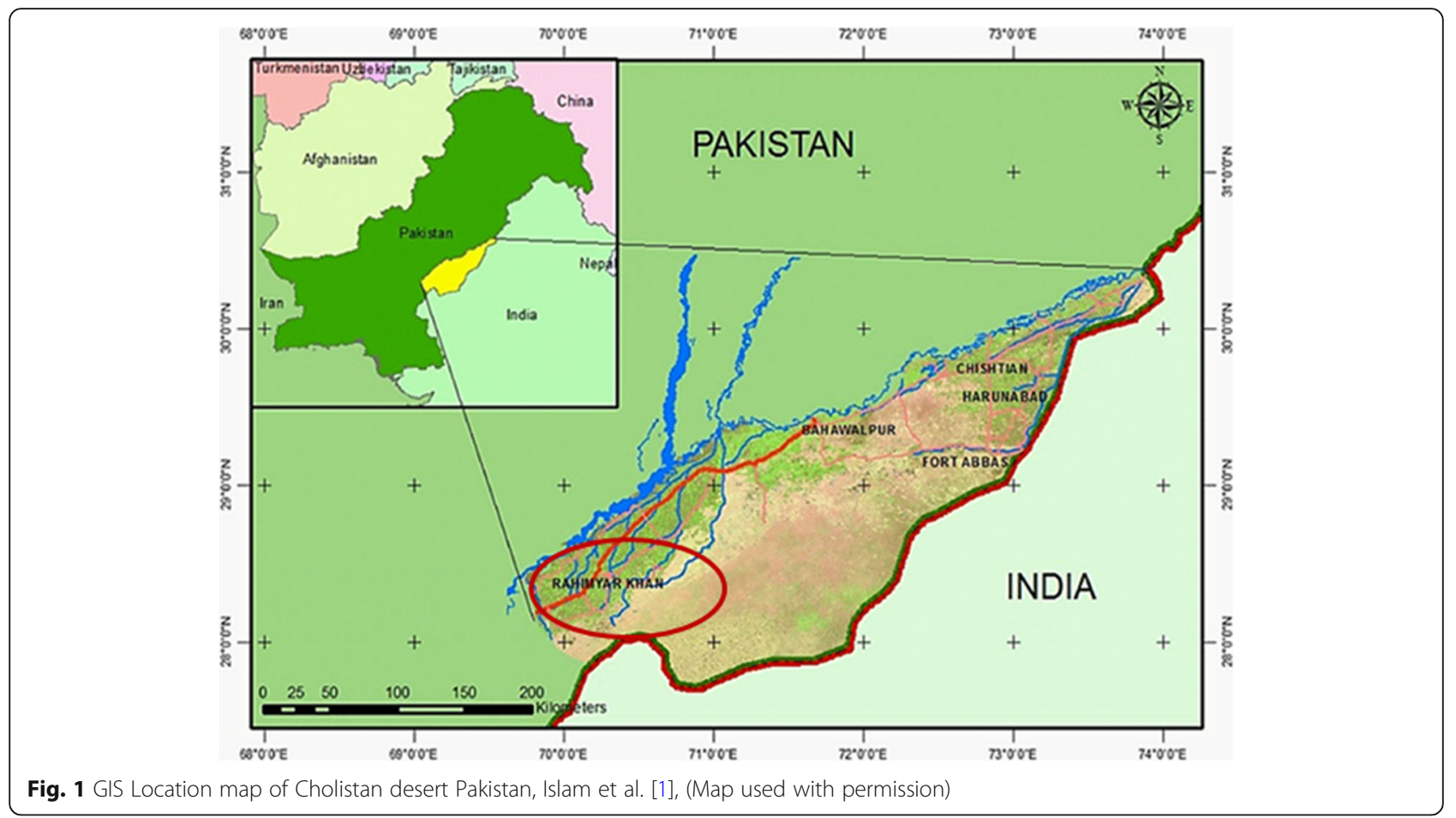

high rate of evaporation $[2,3]$. The soil is very poor in organic matter and it may possess unique actinomycetes with unusual antibacterial activity. Although the actinomycetes are present in various environments like soil, fresh water, marines, in the plant tissues etc. but those present in unexplored habitats may have some unique characteristics to live in such habitats and to produce unique secondary metabolites [4]. These are abundantly present in soil of different types, but the arid habitats like deserts are now becoming the target ecosystems for their search because of the uniqueness of environmental conditions.

Because of the ease of access to antibiotics, the misuse of these drugs has been increased, as a result we are lacking in having a perfect antibiotic which can eradicate the pathogens without causing harmful side effects [5]. New antibiotics are required to fight against the counterfeiting pathogens that have developed resistance against existing antibiotics [6]. Methicillin resistant Staphylococcus aureus (MRSA) has been designated as one of the major hazardous pathogens associated with the development of antimicrobial resistance (AMR). The advent of AMR in $S$. aureus is widely recorded in Pakistan and around the globe and the species has proven particularly skilled at evolving resistance in the face of new antibiotic challenges. Therefore, the search for unrevealed species is critically needed to address this emerging problem and there is a recommendation to explore the untapped environments like deserts, caves etc [7].The exploration of new species of actinobacteria will likely give a chance to discover potentially new structural and beneficial secondary metabolites. The actinomycetes isolated from deserts have the capability to survive the harsh conditions of weather like high $\mathrm{pH}$ of the soil and salinity, and they possess unusual gene clusters for the production of unique and potent antibacterial compounds [8].

Different techniques are being used to identify these unique bacterial species and the compounds produced by them like microscopic analysis [9]. Microscopic studies especially scanning electron microscopic (SEM) examination of different species of actinomycetes provides useful information about their ultra-structures. The spores are considered to be the electron dense structures and the examination of their surfaces and arrangement in the form of chains and clusters has been studied by SEM. The spore arrangement is considered as an important criterion for the determination of the taxonomic position of actinomycetes in different groups. The use of SEM is increasing for the classification of actinomycetes because of its higher magnification and great focal strength [10]. Now, very high quality polycarbonate filters are available with different pore sizes for the collection of viruses and bacteria which are suitable for their surface observation using SEM [11].

A little information is present regarding the actinomycetes isolated from harsh and arid ecosystems, which are considered as the most bountiful environments for the discovery of new bacteria and compounds [8]. In our previous report [12], we reported the identification and antimicrobial activity of some selected strains from this ecosystem against methicillin resistant Staphylococcus 
aureus (MRSA), with major emphasis on the identification and validation of MRSA strains from clinical samples. This study reports a detailed account of the search and screening of the unique and extreme ecological niche; the Cholistan desert, Pakistan for the culture-able spore forming actinobacterial diversity, along with the in depth chemical profiling of the bioactive compounds produced by them. We believe that this ecosystem has not been studied for the detailed actinobacterial diversity, so this seems to be the first comprehensive report on culture-able spore forming actinobacterial diversity of the Cholistan desert Pakistan.

\section{Methods}

\section{Sample collection}

The 20 soil samples were collected in polythene bags from various sites in Cholistan desert Pakistan. The samples were obtained at least $1-2 \mathrm{~km}$ distance from each other. These samples were then processed first by applying different physical and chemical treatments (Heat treatment was given at $50-55{ }^{\circ} \mathrm{C}$ for $2-16 \mathrm{~h}$ and chemical treatment was given by mixing the soil sample with $\mathrm{CaCO}_{3}$ in the ratio $10: 1(\mathrm{w} / \mathrm{w})$ followed by incubation at room temperature for 7-9 days in humid environment) by adopting the methods narrated by Hayakawa and Nonomura [13] for the selection of actinobacteria.

\section{Isolation of Actinobacteria}

For the isolation of actinobacterial strains, serial dilution method was adopted for each sample. Two different isolation media were used according to the guidelines of International Streptomyces Project (ISP) for the isolation of variety of strains: glycerol-casein- $\mathrm{KNO}_{3}$ agar (Sigma) and actinomycete isolation agar (media recipes are included in additional file 1) were prepared and sterilized by autoclaving. To prevent or suppress the fungal growth, cycloheximide $(20 \mathrm{mg} / \mathrm{L})$ was added in the media after autoclaving. The serial dilutions of the samples were prepared and $50 \mu \mathrm{l}$ of the dilutions $10^{-2}$ and $10^{-3}$ were spreaded on isolation media, followed by incubation at $28^{\circ} \mathrm{C}$ for 7 to 15 days for both of the media. The prospective actinobacterial colonies were chosen from media plates and were streaked on the enriched medium i.e. Yeast extract-malt extract (GYM) agar (Sigma) [14] and then purified by repeated streaking on GYM agar. The pure cultures were preserved as glycerol stocks at $-80^{\circ} \mathrm{C}$ in the microbial storage facility at the Department of Microbiology and Molecular Genetics (MMG), University of the Punjab (a redundant copy of the strains has also been stored in the collaborating laboratory at the Department of Pharmaceutical Sciences, College of Pharmacy, University of Kentucky). The strains were initially screened for the antimicrobial activity against MRSA by the agar plug method or the so called solid media bioassay [15] and active strains in whole collection were detected (Additional file 2; Table S1).

\section{Taxonomic characterization of the Actinobacterial strains}

A polyphasic taxonomic approach was adopted for the identification of the isolated strains. All of the strains were studied for morphological, physiological and biochemical characteristics, along with the 16S rRNA gene sequencing of the 30 representative strains. The morphological characterization was performed with the pure and individual strains by following the methods of Bensultana et al. [16]. The features observed, included colony morphology, color of aerial and substrate mycelia and pigmentation. The strains were probed for biochemical features including the production of melanin, utilization of different sugars, organic acid formation, utilization of oxalate and organic acid, hydrolysis of esculin \& urea.

For genetic characterization, the DNA of actinobacterial strains was extracted from mycelial part, using tissue genomic DNA extraction kit (FavorPrep $^{\text {tw }}$, Cat\# FATGK001-1). The 16S rRNA gene sequence of these DNA samples were amplified by PCR amplification, using universal primers (27f: AGAGTTTGATCCTG GCTCAG) and (1522r: AAGGAGGTGATCCARCCGC A) [17]. The PCR reaction mixture included $5 \mu \mathrm{l}$ of DNA sample, $2 \mu$ lof each primer with working concentration of $10 \mathrm{pmol}$ and $25 \mu \mathrm{l}$ of $2 \mathrm{X}$ PCR master mixes (THERMO-scientific DreamTaq Green Master Mix). The reaction conditions were as follows: $95^{\circ} \mathrm{C}$ for $1 \mathrm{~min}$, 30 cycles of $95^{\circ} \mathrm{C}$ for $30 \mathrm{~s}$, annealing at $55^{\circ} \mathrm{C}$ for $30 \mathrm{~s}$, extension at $72^{\circ} \mathrm{C}$ for $30 \mathrm{~s}$ followed by final extension for 5 min at $72^{\circ} \mathrm{C}$ [18]. Amplified products were purified by employing the protocol described in gel purification kit (FavorPrep $^{\mathrm{Tw}}$, Cat\# FAGPK001-1), then sequenced on an automated sequencer. The sequenced data obtained was BLAST analyzed at the NCBI [19] as well as at EzBioCloud database [20], for determining the similarity with type strains. The analyzed sequences of each strain were deposited to the NCBI GenBank to get the accession numbers. The evolutionary history was inferred by constructing phylogenetic tree by Neighbor-Joining method using 1000 replicates bootstrap value [21, 22]. The evolutionary distances were computed using the Maximum Composite Likelihood method [23] and are in the units of the number of base substitutions per site. Evolutionary analyses were conducted in MEGA6 [24].

\section{Scanning Electron microscopy (SEM)}

The ultra-structure of mycelium and arrangement of spores of representative desert actinobacterial strains was observed by using scanning electron microscopy following the procedure described by Cavaletti et al. [25]. A 
small piece of GYM agar from the purified culture plate of actinobacteria was trimmed with a sterilized scalpel and fixed with a solution of cacodylate buffer having 5\% formaldehyde and $2 \%$ glutaraldehyde $(0.1 \mathrm{M}$ cacodylate, $0.01 \mathrm{M} \mathrm{CaCl}_{2}, 0.01 \mathrm{M} \mathrm{MgCl}_{2}, 0.09 \mathrm{M}$ sucrose; $\mathrm{pH}$ 6.9) for $3 \mathrm{~h}$ on ice and washed with the cacodylate buffer. Dehydration of the samples was done by using different grades of acetone $(10,30,50,70,90$, and $100 \%$ acetone) and each step was performed on ice block for $30 \mathrm{~min}$. After that the samples were dried by using liquid $\mathrm{CO}_{2}$ and covered with an approximately $10 \mathrm{~nm}$ thick gold film by spattered coating. These samples were then observed under a range of magnifications $(5.00 \mathrm{kx}, 10.0 \mathrm{kx}$, $15.0 \mathrm{kx}, 20.0 \mathrm{kx}, 25.0 \mathrm{kx}, 40.0 \mathrm{kx}$ and $50.0 \mathrm{kx}$ ) with acceleration voltage $5.0 \mathrm{kV}, 7.0 \mathrm{kV}$ and $10.0 \mathrm{kV}$ in VEGA3 (TESCAN) Scanning Electron Microscope by using SE (secondary electron) detector.

\section{Preparation of Methanolic extracts of desert Actinobacteria}

The desert actinobacterial isolates were grown on lab scale as shaking flask cultures (250-500 ml GYM broth) and the crude extracts were obtained by solvent-solvent extraction using a separating funnel. The equal volumes of culture broth and ethyl acetate were mixed in the separating funnel and shaken for about $15 \mathrm{~min}$, after which the mixture was allowed to settle down. After the two distinct layers appeared, the upper organic layer was retrieved carefully and the procedure was repeated thrice. The ethyl acetate was then evaporated on rotary vacuum evaporator (Heidolph Laborota 4000 efficient, Type\# D-91126 Schwabach) and the extract was dissolved in analytical grade methanol.

\section{Determination of antibacterial activity against MRSA}

The antimicrobial activity of desert actinobacterial strains was determined at two levels, initially all the isolated 110 strains were screened by agar plug method against one MRSA strain and active strains were selected. Later the active strains were further screened by well diffusion methods against the 10 MRSA strains. For this purpose ten strains of MRSA were collected from a diagnostic laboratory (Citi Lab, Lahore). These strains were confirmed as MRSA by performing different biochemical tests (catalase and DNase), through disc diffusion antibiotic assay using a panel of 10 antibiotics discs including methicillin $(10 \mu \mathrm{g})$, oxacillin $(1 \mu \mathrm{g})$, cefoxitin $(30 \mu \mathrm{g})$, ampicillin $(10 \mu \mathrm{g})$, amikacin $(30 \mu \mathrm{g})$, amoxicillin $(25 \mu \mathrm{g})$, cephalexin $(30 \mu \mathrm{g})$, cefoperazone $(75 \mu \mathrm{g})$, ciprofloxacin $(5 \mu \mathrm{g})$ and piperacillin $(100 \mu \mathrm{g})$ according to the CLSI standards [26]. The validation of these strains was also established genetically by mec- $A$ gene and $16 \mathrm{~S}$ rRNA gene sequencing [12] (GenBank Accession numbers: KU662352-KU662355, KR862284, KR862285, KR862287- KR862289, KR862291).

The discs of agar $(5 \mathrm{~mm})$ were cut from the pure culture plates of actinobacterial strains and placed on the MH (Muller Hinton agar) plates swabbed with MRSA isolate and zones of inhibition were recorded after overnight incubation [27]. The well diffusion method was performed by loading $60 \mu \mathrm{l}$ of methanolic extracts of actinobacterial isolates in the wells $(5 \mathrm{~mm}$ diameter) made in $\mathrm{MH}$ agar swabbed with MRSA isolate. The zones of inhibition were measured around the wells after overnight incubation [27].

\section{Chemical profiling of the Actinobacterial strains}

The methanolic extracts of the bioactive actinobacterial strains were screened for their chemical profile by employing three chromatographic techniques: thin layer chromatography, high performance liquid chromatography (HPLC) and LC-MS.

\section{Thin layer chromatography}

Crude extracts of actinobacterial strains were tested on TLC plates (TLC silica gel $60 \mathrm{~F}_{254}$, Merck, Germany) to assess the nature of secondary metabolites produced by them. Each of the extracts was superimposed onto two TLC plates by repeated spotting using a small capillary. The loaded plate was run in $10 \%$ methanol/dichloromethane solvent system and visualized in UV light (two wavelengths were used i.e., $254 \mathrm{~nm}$ and $366 \mathrm{~nm}$ ) using a UV lamp (CAMAG). After the development, one plate was stained with anisaldehyde $/ \mathrm{H}_{2} \mathrm{SO}_{4}$ spraying reagent (anisaldehyde, methanol, $\mathrm{H}_{2} \mathrm{SO}_{4}$, acetic acid) while the

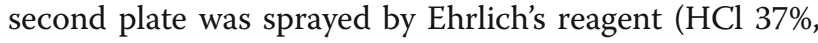
4-dimethylamino benzaldehyde, methanol) in order to determine different colored bands of the compounds in the extracts.

\section{High performance liquid chromatography (HPLC-UV/Vis) analysis}

HPLC-UV/Vis analysis of crude extracts of actinobacterial strains was carried out on clarity chromatography software in Sykum ${ }^{\circ}$ S1122 delivery system. The separation of the components of secondary metabolites was carried out by using RPC18 column (ThermoHypersil-Keystone, $250 \times 4.6 \mathrm{~mm}$, particle size: $5 \mu \mathrm{m}$ ) which act as a stationary phase. The mobile phase was methanol and water (9:1) while the rate of flow was set at 1 $\mathrm{ml} / \mathrm{min}$. Various peaks were observed in the UV chromatograms of the samples which were compared later with the UV chromatographic data of secondary metabolites to interpret the type of compounds produced by the actinobacterial strains. 
High performance liquid chromatography- mass spectrometry (HPLC-MS) analysis

HPLC-MS analysis of the most active actinobacterial extracts was performed on the Agilent 6120 Quadrupole MSD mass spectrometer (Agilent Technologies, Santa Clara, CA, USA) equipped with an Agilent 1200 Series Quaternary LC system and an Eclipse XDB-C18 column $\left(150 \times 4.6 \mathrm{~mm}, 5 \mu \mathrm{m}\right.$; solvent $\mathrm{A}: \mathrm{H}_{2} \mathrm{O} / 0.1 \%$ formic acid, solvent $\mathrm{B}: \mathrm{CH}_{3} \mathrm{CN} / 0.1 \%$ formic acid; flow rate: $0.4 \mathrm{ml}$ $\min ^{-1}$; 0-4 min, $10 \%$ B; 4-22 min, $10-100 \%$ B; $22-27$ min, $100 \%$ B; $27-29$ min, $100-10 \%$ B; $29-35$ min, $10 \%$ B). The molecular masses on each of the ion peak were calculated in all the extracts and the data was analysed by comparison with the already reported Streptomyces compounds in the AntiBase [28].

\section{Results}

Taxonomic characteristics of the selected Actinobacterial strains

A total of 110 actinobacterial strains were recovered from the desert soil and sand samples. Most of the strains produced hard, embedded and rough textured colonies with different sizes and regular or irregular margins. A variety of colors of aerial mycelia were observed in different strains including white, yellowish white, yellow, purple, orange and pink etc, similarly the substrate mycelia displayed the colors including white, yellowish, brown, light pink, purple and orange etc (Table 1, Additional file 3: Table S2, Additional file 4: Figure S1. The diffused pigments were observed only in 3 strains including, AFD1 (brown), AFD15 (light brown) and in AFD26 (dark yellow) (Table 1, Additional file 3: Table S2, Additional file 4; Figure S1).

In case of the testing of different sugars as sole source of carbon, the glucose and mannose were utilized by all of the strains except the strain, AFD23. Similarly fructose was used as carbon source by most of the strains, except four strains including AFD6, AFD14, AFD20 and AFD26 (Table 2). Sixteen of the strains exhibited the tyrosinase activity and production of melanin. Most of the strains showed hydrolysis of urea and esculin, utilization of organic acids and oxalate etc. Similarly most of the strains were found positive in case of organic acid formation and lecithovitellin reaction (Table 2, Additional file 3: Table S2).

In scanning electron microscopy using VEGA3 (TESCAN), different magnifications $(5.0 \mathrm{kx}, 10.0 \mathrm{kx}, 20.0 \mathrm{kx}$, $25.0 \mathrm{kx}, 40.0 \mathrm{kx}$, and $50.0 \mathrm{kx}$ ) revealed ultra-fine structure of the cells and arrangements of spores of actinobacterial strains, the best results were obtained by using $40.0 \mathrm{kx}$ magnification (Fig. 2). As it can be seen in Fig. 2, the arrangement of spores in the form of chains is clear for all the isolates. In case of the strain AFD1, best results were obtained at higher magnification i.e. $25 \mathrm{kx}$.
The spores are grouped in the form of chains with lateral depressions (Fig. 2a and b). In case of the strain AFD7 the spores can be seen entangled with each other to form the aerial mycelium on the agar surface. At higher magnification of the SEM $(25 \mathrm{kx})$ the typical arrangement of the spores i.e. Retinaculiaperti [29] of this strain is clear (Fig. 2c and d). Some of the strains have unique pattern of spores arrangement as in case of strain AFD8 (Fig. 2e), showing a sheath of cells while in the Fig. $2 \mathrm{f}$ the spores are emerging from the cells like spines. Another unique arrangement was shown by the strain AFD16 (Fig. 2g, h) in which the spores are entangled to form an interlocking pattern. In case of the strain AFD19 long and mature spores can be seen as 10-50 spores per spore chain (Fig. 2i, j). In some strains, spiny surfaced spores can be seen with central depressions like in the case of strain AFD26 (Fig. 2k, l). The morphological (colony characteristics), microscopic (SEM), biochemical and physiological characteristics suggested that most of the isolated strains are the members of genus Streptomyces on comparison of the features with those of reported in the literature $[29,30]$.

The 16S rRNA gene sequences and BLAST analysis at EzBioCloud database [20] of the 29 representative strains showed \%similarity with different actinobacterial type strains. In 25 of the cases \%similarity in the range of 99 to $100 \%$ was observed with different species of the genus Streptomyces (Table 3). However 4 strains exhibited \%similarity between 98 to $99 \%$, such as strain AFD6 exhibited 98.68\% similarity with the type strain Streptomyces fradiae (MIFZ01000280), the strains AFD23 and AFD26 exhibited 98.27 and $98.94 \%$ respectively, the \%similarity with the type strain Streptomyces albaduncus (AY999757), the strain AFD29 showed 98.97\% similarity with type strain Streptomyces europaeiscabiei (NR042790). While 1 strain AFD13 exhibited $97.02 \%$ similarity with the type strain Streptomyces roseofulvus (AB184327) (Table 3). Two of the strains exhibited \%similarity with the type strains of genera other than Streptomyces, including the strain AFD18 showed 99.65\% similarity with the type strain Saccharothrix xinjiangensis (AB381939), while the strain AFD22 showed $99.89 \%$ similarity with the type strain Arthrobacter ANPE_s (ANPE02000028) (Table 3).

The neighbor joining phylogenetic tree constructed based on the 16S rRNA gene sequence data of the 29 strains, shows the phylogenetic relation of the strain with each other. The optimal tree with the sum of branch length $=32.44194265$ is shown in Fig. 3 . The tree is drawn to scale, with branch lengths in the same units as those of the evolutionary distances used to infer the phylogenetic tree. The evolutionary distances were computed using the Maximum Composite Likelihood method [23] and are in the units of the number of base substitutions per site. The analysis involved 49 nucleotide sequences, for which the NCBI GenBank accession 
Table 1 Morphological characteristics of the selected Cholistan desert actinobacterial strains observed on GYM agar after cultivation at $28^{\circ} \mathrm{C}$ for one week

\begin{tabular}{|c|c|c|c|c|c|c|c|c|}
\hline \multirow[t]{2}{*}{ Strains } & \multirow{2}{*}{$\begin{array}{l}\text { alsolation } \\
\text { codes }\end{array}$} & \multirow[t]{2}{*}{ Growth Pattern } & \multicolumn{2}{|l|}{ Color of Mycelium } & \multirow{2}{*}{$\begin{array}{l}\text { Diffused } \\
\text { pigment }\end{array}$} & \multicolumn{3}{|l|}{ Colony characteristics } \\
\hline & & & Substrate Mycelium & Aerial Mycelium & & Consistency & Size mm & Shape \\
\hline AFD1 & AD3 & Well grown & White & Grayish white & Brown & Hard \& embedded & 3 & Round \\
\hline AFD2 & AD6 & Well grown & Light yellow & Yellowish white & No pigment & Hard \& embedded & 3 & Round \\
\hline AFD3 & AD10 & Well grown & Grayish white & White & No pigment & Hard \& embedded & 4 & Round \\
\hline AFD4 & AD15 & Well grown & Light pink & Whitish yellow & No pigment & Soft with spores & 2 & Round \\
\hline AFD5 & AD20 & Moderate growth & White & Yellowish white & No pigment & Hard \& embedded & 2 & Round \\
\hline AFD6 & AD21 & Well grown & Brown & Yellow & No pigment & Hard \& embedded & 3 & Round \\
\hline AFD7 & AD23 & Well grown & Yellowish white & White & No pigment & Hard \& embedded & 2 & Round \\
\hline AFD8 & AD29 & Well grown & White & Yellowish white & No pigment & Hard \& embedded & 3 & Round \\
\hline AFD9 & AD34 & Well grown & Light pink & White & No pigment & Soft with spores & 2 & Round \\
\hline AFD10 & AD37 & Well grown & Purple pink & Purple & No pigment & Hard \& embedded & 2 & Round \\
\hline AFD11 & AD38 & Moderate growth & Yellowish white & White & No pigment & Hard with less spores & 3 & Round \\
\hline AFD12 & AD42 & Well grown & White & Whitish grey & No pigment & Hard \& embedded & 3 & Round \\
\hline AFD13 & AD48 & Well grown & Light orange & Yellowish orange & No pigment & Hard \& embedded & 3 & Round \\
\hline AFD14 & AD54 & Well grown & Purple pink & Purple & No pigment & Soft with spores & 2 & Round \\
\hline AFD15 & AD57 & Well grown & Brown & Light brown & Light brown & Hard \& embedded & 3 & Round \\
\hline AFD16 & AD59 & Well grown & White & Greenish brown & Brown & Hard \& embedded & 2 & Round \\
\hline AFD17 & AD61 & Well grown & Yellowish white & White & No pigment & Hard \& embedded & 3 & Round \\
\hline AFD18 & AD63 & Well grown & Yellowish white & Yellow & No pigment & Hard \& embedded & 3 & Round \\
\hline AFD19 & AD68 & Well grown & Purple pink & Purple & No pigment & Hard \& embedded & 2 & Round \\
\hline AFD20 & AD69 & Well grown & White & Grey white & No pigment & Hard \& embedded & 2 & Round \\
\hline AFD21 & AD73 & Well grown & Orange yellow & Orange & No pigment & Hard \& embedded & 3 & Round \\
\hline AFD22 & AD76 & Well grown & Orange white & Orange & No pigment & Hard \& embedded & 2 & Round \\
\hline AFD23 & AD80 & Well grown & Yellow white & Yellow & No pigment & Soft with spores & 2 & Round \\
\hline AFD24 & AD81 & Well grown & White & Yellowish white & No pigment & Hard \& embedded & 2 & Flower shaped \\
\hline AFD25 & AD85 & Moderate growth & Purple & Pink & No pigment & Hard \& embedded & 3 & Round \\
\hline AFD26 & AD89 & Well grown & Meroon or dark brown & Yellowish white & Dark Yellow & Hard \& embedded & 2 & Round \\
\hline AFD27 & AD96 & Well grown & Brown & White brown & Yellow & Hard \& embedded & 3 & Round \\
\hline AFD28 & AD100 & Well grown & Yellowish white & White & No pigment & Hard \& embedded & 3 & Round \\
\hline AFD29 & AD104 & Well grown & White & Whitish grey & No pigment & Hard \& embedded & 2 & Round \\
\hline AFD30 & AD107 & Moderate growth & White & Yellowish white & No pigment & Hard \& embedded & 2 & Round \\
\hline
\end{tabular}

${ }^{a}$ the strains were designated by specific number codes based on the sequence of isolation at the time of selection from a sample

numbers are given in parenthesis. Codon positions included were 1 st $+2 n d+3 r d+$ Noncoding. All positions containing gaps and missing data were eliminated. There were a total of 254 positions in the final dataset. Evolutionary analyses were conducted in MEGA6 [24]. The numbers at the nodes indicate the levels of bootstrap support based on 1000 replicates. The isolated strains showed phylogenetic relationships with each other and clustered in four major clads, showing various Streptomyces species with common ancestry. The strains made pairwise operational taxonomic units (OTUs) at species level with each other and with the closest match or type strains found by BLAST analysis via EzTaxon server (Fig. 3).

\section{Antibacterial activity of the selected Actinobacteria against MRSA}

The actinobacterial strains displayed prolific antibacterial activity against MRSA isolates. In initial screening by agar plug method among the 110 isolated strains 30 strains showed growth inhibition of the MRSA test strain (Additional file 2: Table S1). The 30 active strains were further investigated for their inhibitory activity by well diffusion assay against a panel of 10 MRSA strains. 
Table 2 Biochemical and physiological characteristics of Cholistan desert actinobacterial strains

\begin{tabular}{|c|c|c|c|c|c|c|c|c|c|c|c|c|c|c|c|c|}
\hline \multirow[t]{2}{*}{ Strains } & \multicolumn{2}{|c|}{ Hydrolysis of } & \multicolumn{2}{|c|}{$\begin{array}{l}\text { Utilization of } \\
\text { organic acids }\end{array}$} & \multirow[t]{2}{*}{ Oxalate utilization } & \multirow[t]{2}{*}{ Organic acid formation } & \multirow[t]{2}{*}{ Lecithovitellin reaction } & \multicolumn{9}{|c|}{ Sugar utilization profile } \\
\hline & Urea & Esculin & $\mathrm{C}$ & $M$ & & & & $\mathrm{MP}$ & DG & DF & LA & $\mathrm{DM}$ & $S$ & I & DGL & $\bar{M}$ \\
\hline AFD1 & + & + & + & + & + & + & + & + & + & + & + & + & + & + & + & + \\
\hline AFD2 & + & + & + & + & + & + & - & + & + & + & + & + & + & + & + & + \\
\hline AFD3 & + & - & + & - & - & + & + & + & + & + & + & - & - & + & + & + \\
\hline AFD4 & + & - & - & - & - & - & - & - & + & + & - & - & + & - & - & + \\
\hline AFD5 & + & + & + & + & + & - & + & - & + & + & + & + & - & + & - & + \\
\hline AFD6 & - & + & - & + & - & + & + & + & + & - & + & + & - & - & + & + \\
\hline AFD7 & + & - & - & - & - & - & - & + & + & + & - & + & - & - & - & + \\
\hline AFD8 & + & + & + & - & + & - & + & - & + & + & + & - & - & + & - & + \\
\hline AFD9 & + & + & + & + & + & + & - & + & + & + & + & + & + & + & + & + \\
\hline AFD10 & + & + & + & + & + & + & + & - & + & + & + & + & + & + & + & + \\
\hline AFD11 & + & - & - & - & - & + & - & - & + & + & - & + & - & + & + & + \\
\hline AFD12 & + & - & + & - & - & - & - & + & + & + & - & + & - & + & - & + \\
\hline AFD13 & + & + & - & + & + & - & + & + & + & + & + & - & - & - & - & + \\
\hline AFD14 & - & + & - & + & + & - & + & - & + & - & + & - & - & - & - & + \\
\hline AFD15 & + & + & - & + & + & + & + & + & + & + & + & - & - & - & + & + \\
\hline AFD16 & + & - & - & - & - & - & - & - & + & + & - & - & - & - & - & + \\
\hline AFD17 & + & - & - & - & - & - & - & - & + & + & - & - & - & - & - & + \\
\hline AFD18 & + & + & - & + & + & + & + & + & + & + & + & - & - & - & + & + \\
\hline AFD19 & + & + & - & + & + & - & + & - & + & + & + & - & + & - & - & + \\
\hline AFD20 & - & + & - & + & + & - & + & + & + & - & + & - & - & - & - & + \\
\hline AFD21 & + & - & + & - & - & + & - & + & + & + & - & + & - & + & + & + \\
\hline AFD22 & + & + & + & + & + & + & + & + & + & + & + & + & + & + & + & + \\
\hline AFD23 & + & - & + & - & - & - & - & + & + & + & - & + & - & + & - & - \\
\hline AFD24 & + & + & + & + & + & + & + & - & + & + & + & + & + & + & + & + \\
\hline AFD25 & + & + & + & + & + & + & + & - & + & + & + & + & - & + & + & + \\
\hline AFD26 & - & + & + & + & + & + & + & - & + & - & + & + & - & + & + & + \\
\hline AFD27 & + & - & - & - & - & + & - & + & + & + & - & + & - & - & + & + \\
\hline AFD28 & + & - & - & - & - & + & - & - & + & + & - & + & - & - & + & + \\
\hline AFD29 & + & - & - & - & - & - & - & + & + & + & - & - & - & - & - & + \\
\hline AFD30 & + & + & - & + & + & + & + & - & + & + & + & - & - & - & + & + \\
\hline
\end{tabular}

Key: $C$ citrate, $M$ Melonate, MP melanin production, $D G$ D-glucose, DF D-fructose, LA L-arabinose, DM D-mannitol, S Sucrose, I Inositol, DGL D-galactose, $M$ Mannose, $(+)=$ positive result, $(-)=$ negative result

In this secondary screening the most active strain was Streptomyces pseudogriseolus AFD2 which exhibited the maximum zone of inhibition up to $32 \mathrm{~mm}$ against the MRSA strain A11. The strain AFD4 displayed maximum zone of inhibition $(18 \mathrm{~mm})$ against MRSA strain A5. In the case of strain AFD7, maximum zone of inhibition was recorded to be $24 \mathrm{~mm}$. The strain AFD8 exhibited maximum zone of inhibition against MRSA strain A1 and A5 i.e., $17 \mathrm{~mm}$. The strain AFD9 showed maximum zone of inhibition $21 \mathrm{~mm}$ against MRSA strain A2. The strain AFD10 also exhibited very potent antibacterial activity with zone of inhibition of $20 \mathrm{~mm}$ against MRSA strains A2, A6 and A14. The strain AFD14 showed maximum zone of inhibition i.e., $23 \mathrm{~mm}$ against MRSA strain A7. The strain AFD15 exhibited maximum zone of inhibition against MRSA strain A9 i.e., $21 \mathrm{~mm}$. Among other desert actinobacterial strains, another highly active strain was AFD16; it exhibited zone of inhibition up to $20 \mathrm{~mm}$ against MRSA strains A1, A5, A6 and A9. In the case of strain AFD20 maximum zone of inhibition recorded was $27 \mathrm{~mm}$ against MRSA strain A8 while in case of strain AFD21 maximum zone of inhibition recorded was $19 \mathrm{~mm}$ against MRSA strains A1, A5, A6 and A9. The strain AFD22 showed $26 \mathrm{~mm}$ zone of 


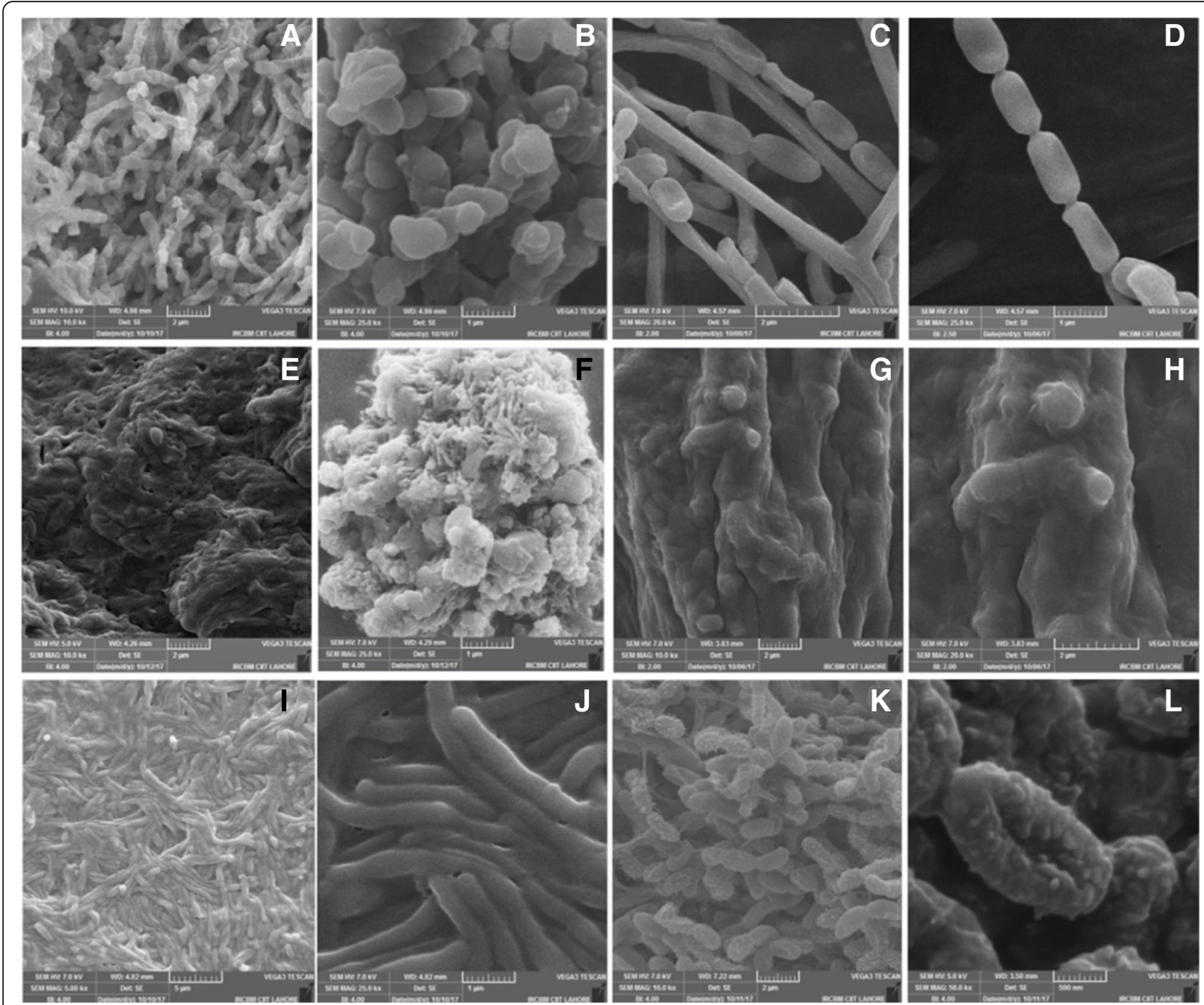

Fig. 2 Scanning electron microscope images of Cholistan desert actinobacteria under different magnifications: Strain AFD1 (a) 10.0 kx, (b) 25.0 kx; Strain AFD7 (c) 20.0 kx, (d) 25.0 kx; Strain AFD8 (e) 10.0 kx, (f) 25.0 kx; Strain AFD16 (g) 10.0 kx, (h) 20.0 kx; Strain AFD19 (i) 5.0 kx (j) 40.0 kx; Strain AFD26 (k) $10.0 \mathrm{kx}$ (I) $50.0 \mathrm{kx}$

inhibition against MRSA isolates A1 and A14 (Table 4, Additional file 5: Figures S2A, S2B, S2C and S2D).

\section{Chemical profiling of the Methanolic extracts of Cholistan Desert Actinobacteria}

In TLC analysis, the UV visible bands were observed at $254 \mathrm{~nm}$ and $366 \mathrm{~nm}$ wave length. The methanolic extracts of the strains AFD7, AFD9, AFD10, AFD20, AFD22, AFD24 and AFD26 developed some distinct bands when viewing in UV light (Additional file 5: Figure S2E, S2F). Different colored bands were observed in the extracts of the strains AFD9, AFD10, AFD20, AFD22 and AFD24 after treatment with anisaldehyde reagent. The spots of different colors like violet, blue, green, yellow and orange were seen after heating which expressed the presence of different structural classes of secondary metabolites like quinolones and actinomycins etc [31].

The HPLC-UV analysis of the crude extracts of the active strains exhibited varied peaks. For example, the crude extract of the actinobacterial strain AFD2 produced 3 prominent and many minor peaks, the highest was observed at $9.323 \mathrm{~min}$, then at $2.876 \mathrm{~min}$ and 4.144 min (Additional file 6: Figure S3). The crude extract of another active strain AFD7 showed 6 peaks, the major was at retention time $4.113 \mathrm{~min}$ (Additional file 7: Figure S7). Besides these the crude extracts of other strains like AFD4, AFD8, AFD10, AFD12 and AFD26 also exhibited variety of peaks at different retention 
Table 3 GenBank accession numbers of the selected actinobacterial strains and their similarities (percentage) with previously reported strains

\begin{tabular}{|c|c|c|c|c|}
\hline Actino bacterial strains & Sequences submitted & GenBank accession numbers & Closely related taxa & Percentage similarity \\
\hline AFD1 & $657 \mathrm{bp}$ & MH552995 & $\begin{array}{l}\text { Streptomyces setonii } \\
\text { (MUNB01000146) }\end{array}$ & $100 \%$ \\
\hline AFD2 & 992 bp & KX768011 & Streptomyces pseudogriseolus (MUNG01000290) & $99.8 \%$ \\
\hline AFD3 & 978 bp & KX768009 & Streptomyces canarius (AB184396) & $99.69 \%$ \\
\hline AFD4 & 877 bp & MH553082 & $\begin{array}{l}\text { Streptomyces sedi } \\
\text { (EU925562) }\end{array}$ & $100 \%$ \\
\hline AFD5 & $868 \mathrm{bp}$ & MH595998 & $\begin{array}{l}\text { Streptomyces phaeofaciens } \\
\text { (AB184360) }\end{array}$ & $99.98 \%$ \\
\hline AFD6 & $1059 \mathrm{bp}$ & KX131166 & Streptomyces fradiae (MIFZ01000280) & $98.68 \%$ \\
\hline AFD7 & $190 \mathrm{bp}$ & MG271834 & Streptomyces fradiae (MIFZ01000280) & $99.47 \%$ \\
\hline AFD8 & $948 \mathrm{bp}$ & MH553090 & $\begin{array}{l}\text { Streptomyces stramineus } \\
\text { (AB184720) }\end{array}$ & $100 \%$ \\
\hline AFD9 & $1006 \mathrm{bp}$ & KX768010 & Streptomyces iakyrus (JNXI01000062) & $99.90 \%$ \\
\hline AFD10 & $349 \mathrm{bp}$ & KX768012 & Streptomyces puniceus (AB184163) & $99.71 \%$ \\
\hline AFD11 & $520 \mathrm{bp}$ & MH553091 & $\begin{array}{l}\text { Streptomyces artemisiae } \\
\text { (EU200685) }\end{array}$ & $100 \%$ \\
\hline AFD12 & 794 bp & KX131167 & Streptomyces werraensis (AB184381) & $99.62 \%$ \\
\hline AFD13 & $711 \mathrm{bp}$ & KX768013 & Streptomyces roseofulvus (AB184327) & $97.02 \%$ \\
\hline AFD14 & $319 \mathrm{bp}$ & KX768014 & Streptomyces puniceus (AB184163) & $100 \%$ \\
\hline AFD15 & 1017 bp & MH607120 & $\begin{array}{l}\text { Streptomyces griseoplanus } \\
\text { (NR118415) }\end{array}$ & $99 \%$ \\
\hline AFD16 & $738 \mathrm{bp}$ & KX816586 & Streptomyces pratensis (JQ806215) & $100 \%$ \\
\hline AFD17 & $891 \mathrm{bp}$ & KX816590 & Streptomyces badius (AY999783) & $99.89 \%$ \\
\hline AFD18 & $858 \mathrm{bp}$ & KX094938 & Saccharothrix xinjiangensis (AB381939) & $99.65 \%$ \\
\hline AFD19 & 742 bp & KX816592 & Streptomyces globisporus (AB184203) & $100 \%$ \\
\hline AFD20 & 1011 bp & KX816587 & Streptomyces puniceus (AB184163) & $99.90 \%$ \\
\hline AFD21 & $972 \mathrm{bp}$ & KX816588 & Streptomyces alboflavus (JNXT01000131) & $99.90 \%$ \\
\hline AFD22 & 891 bp & KX816589 & ANPE_s (ANPE02000028) & $99.89 \%$ \\
\hline AFD23 & $1039 \mathrm{bp}$ & KX131165 & Streptomyces albaduncus (AY999757) & $98.27 \%$ \\
\hline AFD24 & $408 \mathrm{bp}$ & KX816591 & Streptomyces pratensis (JQ806215) & $100 \%$ \\
\hline AFD25 & $787 \mathrm{bp}$ & KX131168 & Streptomyces werraensis (AB184381) & $99.49 \%$ \\
\hline AFD26 & $947 \mathrm{bp}$ & KX131169 & Streptomyces albaduncus (AY999757) & $98.94 \%$ \\
\hline AFD28 & $733 \mathrm{bp}$ & MH553095 & $\begin{array}{l}\text { Streptomyces artemisiae } \\
\text { (EU200685) }\end{array}$ & $99.86 \%$ \\
\hline AFD29 & $868 \mathrm{bp}$ & MH595999 & $\begin{array}{l}\text { Streptomyces europaeiscabiei } \\
\text { (NR042790) }\end{array}$ & $98.97 \%$ \\
\hline AFD30 & $901 \mathrm{bp}$ & MH628040 & $\begin{array}{l}\text { Streptomyces lavendulae } \\
\text { (JOEW01000098) }\end{array}$ & $99.55 \%$ \\
\hline
\end{tabular}

times $\left(t_{R}\right)$ with varied peak areas (Additional files 8: Figure S5, S9, S11, S13, S15 and S17, Additional files 9, 10, 11, 12 and 13).

The LC-MS analysis of the extracts of most active actinobacterial strains displayed an exciting diversity of the components with antibacterial activity. As shown in Table 5, the total ion chromatogram of strain AFD2 showed various peaks at different retention times $\left(t_{R}\right)$ the most prominent of which was observed at $t_{R} 6.38$ min and the molecular mass calculated for this component was $112 \mathrm{Da}$. The comparison of the chemical profile of this component with the compounds in AntiBase gave the closest match with Emimycin, 3, 5-Dimethyl3-oxol-2-on, and Uracil. Similarly the components at $t_{R} 11.03$ and $12.57 \mathrm{~min}$ in this extract gave closest match with various other compounds in AntiBase (Table 5, Fig. 4 and Additional files 14: Figure S4 and S19, Additional file 15).The total ion chromatogram 


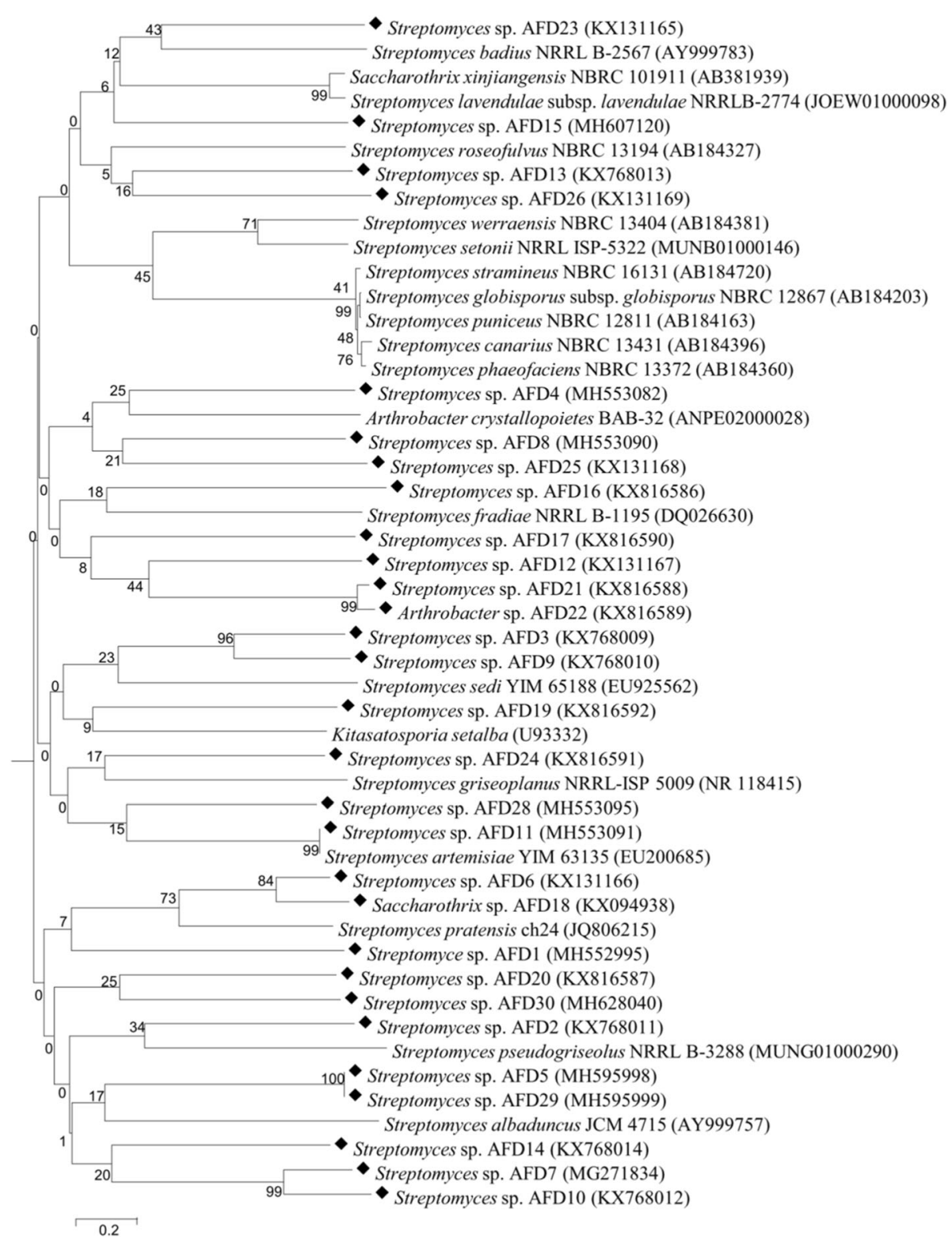

Fig. 3 Molecular Phylogenetic analysis by Neighbor Joining method. The tree showing the interrelationships of isolated actinobacterial strains along with their closely related taxa belonging to Streptomyces, Saccharothrix and Arthrobacter inferred from 16S rRNA gene sequence. Data with gaps were removed after alignment by CLUSTAL W. The rooted tree was constructed using Neighbor Joining method. The analysis involved 49 nucleotide sequences. Codon positions included were 1st $+2 n d+3 r d+$ Noncoding. There were a total of 254 positions in the final dataset. Evolutionary analyses were conducted in MEGA6

of strain AFD4 showed varied peaks at different retention times $\left(t_{R}\right)$, such as a peak at $12.60 \mathrm{~min}$ with molecular mass $136 \mathrm{Da}$. The chemical profile of this component was then compared with the compounds in database and found the closest match with Pyrrole-3yl-2-propenamide, Octalactin $\mathrm{C}$ and Anthranilamide. Likewise the components at $t_{R} 10.23$ and $12.22 \mathrm{~min}$ also showed close matches with the various compounds in the AntiBase (Table 5, Fig. 4 and Additional files 16:
Figure S6, S19, Additional file 15). The total ion chromatogram of the strain AFD7 showed peaks at different retention times such as at $t_{R} 3.83 \mathrm{~min}$, molecular mass for which was calculated as $152 \mathrm{Da}$. The chemical profile of this component was compared with the compounds in AntiBase and the closest matches were observed with Xanthine, Guanazoloand Orsellin-aldehyde. The other components in this extract at other $t_{R}$ $4.50 \mathrm{~min}, 5.77 \mathrm{~min}, 7.10 \mathrm{~min}, 10.24 \mathrm{~min}$ and $11.07 \mathrm{~min}$ 
Table 4 Antibacterial activity of the selected actinobacterial strains against MRSA

\begin{tabular}{|c|c|c|c|c|c|c|c|c|c|c|}
\hline \multirow{2}{*}{$\begin{array}{l}\text { Actinobacterial } \\
\text { strains }\end{array}$} & \multicolumn{10}{|c|}{ Zone of inhibition $(\mathrm{mm})$ against various MRSA strains } \\
\hline & $\bar{A} 1$ & A2 & A5 & A6 & A7 & A8 & A9 & A11 & $\mathrm{A} 12$ & $\mathrm{~A} 14$ \\
\hline AFD1 & 19 & 14 & 18 & 12 & 15 & 14 & 15 & 16 & 13 & 12 \\
\hline AFD2 & 19 & 21 & 17 & 24 & 22 & 24 & 28 & 32 & 25 & 24 \\
\hline AFD3 & 11 & 12 & 19 & 11 & 15 & 14 & 12 & 14 & 11 & 19 \\
\hline AFD4 & 10 & 12 & 18 & 13 & 17 & 14 & 10 & 9 & 16 & 15 \\
\hline AFD5 & 11 & 13 & 15 & 12 & 13 & 15 & 12 & - & 12 & 10 \\
\hline AFD6 & 10 & 12 & 17 & 13 & 16 & 14 & 11 & 9 & 16 & 15 \\
\hline AFD7 & 24 & 22 & 23 & 24 & 25 & 24 & 21 & 20 & 20 & 21 \\
\hline AFD8 & 17 & 15 & 17 & 15 & 16 & 16 & 14 & 15 & 12 & 12 \\
\hline AFD9 & 18 & 21 & 17 & 18 & 13 & 15 & 15 & 16 & 13 & 14 \\
\hline AFD10 & 19 & 20 & 18 & 20 & 17 & 18 & 19 & 18 & 19 & 20 \\
\hline AFD11 & 10 & 12 & 13 & 12 & - & 13 & 14 & - & 11 & 13 \\
\hline AFD12 & 15 & 14 & 15 & 13 & 11 & 12 & 15 & 14 & 13 & 14 \\
\hline AFD13 & 14 & 14 & 15 & 11 & 10 & 12 & 11 & 12 & 12 & 14 \\
\hline AFD14 & 12 & 13 & - & 18 & 23 & 16 & 20 & 10 & - & 10 \\
\hline AFD15 & 11 & 16 & 11 & 11 & 13 & 15 & 21 & 19 & 19 & 13 \\
\hline AFD16 & 20 & 19 & 20 & 20 & 19 & 18 & 20 & 17 & 16 & 19 \\
\hline AFD17 & 12 & 13 & 13 & - & - & 10 & - & - & 10 & 12 \\
\hline AFD18 & 14 & 14 & 15 & 16 & 14 & 13 & 18 & 14 & 18 & 16 \\
\hline AFD19 & 10 & 11 & 12 & 13 & 12 & 10 & 13 & 10 & 11 & 12 \\
\hline AFD20 & 26 & 26 & 18 & 21 & 20 & 27 & 21 & 22 & 24 & 25 \\
\hline AFD21 & 19 & 17 & 19 & 19 & 18 & 16 & 19 & 18 & 16 & 13 \\
\hline AFD22 & 26 & 20 & 21 & 20 & 21 & 22 & 18 & 20 & 23 & 26 \\
\hline AFD23 & 14 & 13 & 12 & 16 & 16 & 14 & 12 & 14 & 10 & 15 \\
\hline AFD24 & 17 & 16 & 17 & 14 & 13 & 17 & 15 & 16 & 16 & 17 \\
\hline AFD25 & 10 & 14 & 11 & 16 & - & 15 & 17 & 10 & 16 & 12 \\
\hline AFD26 & 12 & 13 & 11 & 10 & 15 & 14 & 12 & 14 & 12 & 13 \\
\hline AFD27 & 9 & 9 & 10 & 10 & - & 13 & 11 & 10 & 10 & 14 \\
\hline AFD28 & 17 & 14 & 16 & 24 & 13 & 11 & - & 12 & 11 & 12 \\
\hline AFD29 & 13 & 17 & 14 & 14 & 12 & 14 & 11 & 11 & 10 & 10 \\
\hline AFD30 & 11 & 13 & 11 & 10 & - & 12 & 10 & - & 11 & 10 \\
\hline
\end{tabular}

were also compared in the same manner with the compounds in database and the prospective compounds were suggested (Table 5, Fig. 4 and Additional file 17: Figure S8, S19, Additional file 15).

The total ion chromatogram of strain AFD8 showed various peaks at different retention times, the most prominent of which was observed at $13.42 \mathrm{~min}$, and the molecular mass for this was calculated as $256 \mathrm{Da}$. The chemical profile of this component was then compared in the database and found the closest match with Phenacein, Isobutyryl pyrrothine and Albonoursin. In the same manner the components appeared at other retention times $9.07 \mathrm{~min}, 14.94 \mathrm{~min}$ and $15.58 \mathrm{~min}$ were also compared with the AntiBase (Table 5, Additional file 18: Figure S10, S19, Additional file 15). The total ion chromatogram of strain AFD10 exhibited several peaks at different retention time $\left(t_{R}\right)$ ranging from 9.90-19.42 min and the molecular masses calculated for some of the selected peaks were assigned as $210,136,400$ and $474 \mathrm{Da}$. The chemical profiles of all of these components were also compared with the compounds in AntiBase and found their close matches e.g. the component with molecular mass $400 \mathrm{Da}$ showed the closest match with Daunomycinol, Furaquinocin G, and Daidzein-7- $\alpha-$ L-rhamnoside (Table 5, Additional file 19: Figure S12, S20, Additional file 20). The crude extract of strain AFD12 also exhibited good LC-MS results as it displayed significant peaks at $4.36-16.06 \mathrm{~min}$, with molecular masses range from 111 to $206 \mathrm{Da}$. The chemical profiles of all of these components were compared with the database and found their close matches, e.g. the component detected at $t_{R} 4.36$ min with molecular mass $159 \mathrm{Da}$ showed a close match with 4-(Hydroxymethyl) quinolone and Quinazolinamine (Table 5, Additional files 21: Figure S14, S20, Additional file 20). While strain AFD14, did not show clear mass based on the HPLC-MS analysis (Additional file 22: Figure S16), it displayed an interesting HPLC-UV/Vis profile (Additional file 12: Figure S15). Finally, the crude extract of strain AFD26 exhibited various peaks at retention times $\left(t_{R}\right) /$ molecular masses 6.32 min/112 Da, $6.38 \mathrm{~min} / 163 \mathrm{Da}, \quad 9.49 \mathrm{~min} / 163 \mathrm{Da}, \quad 10.85$ $\mathrm{min} / 163 \mathrm{Da}, 12.23 \mathrm{~min} / 316 \mathrm{Da}$ and $17.43 \mathrm{~min} / 390 \mathrm{Da}$. The chemical profile of all of these components were compared with the data in AntiBase and found the closest matches with reported compounds. For example the component with molecular mass $316 \mathrm{Da}$ showed the close match with Boxazomycin A, 17927-D and Isobutyroxymethyl cyclohex-1(6)-ene-2, 3, 4, 5-tetrol-2-isobutyrate (Table 5, Additional files 23: Figure S18, S20, Additional file 20).

\section{Discussion}

The need for new bioactive metabolites from untapped environments like deserts is mainly stressed due to the drastic consequences and vivacious nature of antibiotic resistance in pathogens. The Cholistan desert of Pakistan is one of those environments which have not been explored yet for the detailed actinobacterial diversity and the search for antimicrobial producing organisms. So, it is anticipated that it may harbor unique and novel species of actinobacteria which can produce new antimicrobial drugs. There is a great need for novel and potential compounds discovery, with their pharmaceutical, industrial or agricultural applications [11]. The actinomycetes are the most authentic sources for new antibiotics because of their varied chemical nature, wide taxonomic 
Table 5 HPLC-MS analyses of the active desert actinobacterial strain

\begin{tabular}{|c|c|c|c|c|c|c|c|c|}
\hline \multirow[t]{2}{*}{ Strains } & \multicolumn{3}{|c|}{$\begin{array}{l}\text { Thin Layer Chromatography (TLC) } \\
\text { Profile }\end{array}$} & \multirow{2}{*}{$\begin{array}{l}\text { HPLC- } \\
\text { Retention } \\
\text { time }\left(t_{R} / \mathrm{min}\right)\end{array}$} & \multirow[t]{2}{*}{$\begin{array}{l}(+) \text { and }(-)- \\
\text { ESI-MS: }(m / z)\end{array}$} & \multirow[t]{2}{*}{$\begin{array}{l}\text { Molecular } \\
\text { Weights }\end{array}$} & \multirow[t]{2}{*}{$\begin{array}{l}\text { Activity against } \\
\text { MRSA }\end{array}$} & \multirow{2}{*}{$\begin{array}{l}\text { Suggested Streptomyces metabolites } \\
\text { from AntiBase } 2017 \\
\text { (Additional files } 15 \text { and 20) }\end{array}$} \\
\hline & $\begin{array}{l}\text { UV } \\
\text { Visualiza }\end{array}$ & & $\begin{array}{l}\text { Staining with } \\
\text { Anisaldehyde } / \mathrm{H}_{2} \mathrm{SO}_{4}\end{array}$ & & & & & \\
\hline$\overline{A F D 2}$ & $\begin{array}{l}254 \mathrm{~nm} \\
366 \mathrm{~nm}\end{array}$ & $\begin{array}{l}4 \text { bands } \\
2 \text { bands }\end{array}$ & $\begin{array}{l}\text { 2green, } \\
1 \text { purple, } \\
\text { 2yellow }\end{array}$ & $\begin{array}{l}6.38 \\
11.03 \\
12.57\end{array}$ & $\begin{array}{l}113[\mathrm{M}+\mathrm{H}]^{+} \\
111[\mathrm{M}-\mathrm{H}]^{-} \\
208[\mathrm{M}+\mathrm{H}]^{+} \\
206[\mathrm{M}-\mathrm{H}]^{-} \\
137[\mathrm{M}+\mathrm{H}]^{+} \\
135[\mathrm{M}-\mathrm{H}]^{-}\end{array}$ & $\begin{array}{l}112 \\
207 \\
136\end{array}$ & $\begin{array}{l}17 \mathrm{~mm} \text { zone of } \\
\text { inhibition against } \\
\text { MRSA A5;32 mm } \\
\text { zone of inhibition } \\
\text { against MRSA A11 }\end{array}$ & $\begin{array}{l}\text { MW=112: Emimycin, 3,5-Dimethyl- } \\
\text { 3-oxol-2-on, Uracil, Enimycin. } \\
\text { MW = 207: Triacsin C, Triacsin D, } \\
\text { Streptazolin, 2-(2-Hydroxypropionyl) } \\
\text { acetanilide, Aeruginol, 7- } \\
\text { Deoxyechinosporin. } \\
\text { MW = 136: Pyrrole-3-yl-2- } \\
\text { propenamide, Anthranilamide, } \\
\text { Octalactin C. }\end{array}$ \\
\hline AFD4 & $\begin{array}{l}254 \mathrm{~nm} \\
366 \mathrm{~nm}\end{array}$ & $\begin{array}{l}3 \text { bands } \\
2 \text { bands }\end{array}$ & $\begin{array}{l}2 \text { purple bands, } \\
1 \text { light blue band, } \\
1 \text { yellow band, } \\
1 \text { green band }\end{array}$ & $\begin{array}{l}10.23 \\
12.22 \\
12.60\end{array}$ & $\begin{array}{l}211[\mathrm{M}+\mathrm{H}]^{+} \\
209[\mathrm{M}-\mathrm{H}]^{-} \\
146[\mathrm{M}+\mathrm{H}]^{+} \\
137[\mathrm{M}+\mathrm{H}]^{+} \\
135[\mathrm{M}-\mathrm{H}]^{-}\end{array}$ & $\begin{array}{l}210 \\
145 \\
136\end{array}$ & $\begin{array}{l}9 \mathrm{~mm} \text { zone of } \\
\text { inhibition against } \\
\text { MRSA A } 11 ; 18 \mathrm{~mm} \\
\text { zone of inhibition } \\
\text { against MRSA A5 }\end{array}$ & $\begin{array}{l}\text { MW = 210: 1-Methoxyphenazine, } \\
\text { 1-Acetyl- } \beta \text {-carboline } \\
\text { MW = 146: Indole-3-carbaldehyde } \\
\text { MW = 136: Pyrrole-3-yl-2- } \\
\text { propenamide, Anthranilamide, } \\
\text { Octalactin C. }\end{array}$ \\
\hline AFD7 & $\begin{array}{l}254 \mathrm{~nm} \\
366 \mathrm{~nm}\end{array}$ & $\begin{array}{l}4 \text { bands } \\
4 \text { bands }\end{array}$ & $\begin{array}{l}2 \text { green bands, } \\
2 \text { yellow bands, } \\
1 \text { blue band }\end{array}$ & $\begin{array}{l}3.83 \\
4.50 \\
5.77 \\
7.10 \\
10.24 \\
11.07 \\
11.38 \\
11.91 \\
13.16 \\
15.05 \\
16.72\end{array}$ & $\begin{array}{l}153[\mathrm{M}+\mathrm{H}]^{+}, \\
151[\mathrm{M}-\mathrm{H}]^{-} \\
202[\mathrm{M}+\mathrm{H}]^{+} \\
261[\mathrm{M}+\mathrm{H}]^{+}, \\
259[\mathrm{M}-\mathrm{H}]^{-} \\
115[\mathrm{M}+\mathrm{H}]^{+} \\
113[\mathrm{M}-\mathrm{H}]^{-} \\
211[\mathrm{M}+\mathrm{H}]^{+} \\
145[\mathrm{M}+\mathrm{H}]^{+} \\
143[\mathrm{M}-\mathrm{H}]^{-} \\
424[\mathrm{M}+\mathrm{H}]^{+} \\
422[\mathrm{M}-\mathrm{H}]^{-} \\
407[\mathrm{M}+\mathrm{H}]^{+} \\
405[\mathrm{M}-\mathrm{H}]^{-} \\
494[\mathrm{M}+\mathrm{H}]^{+} \\
231[\mathrm{M}+\mathrm{H}]^{+} \\
229[\mathrm{M}-\mathrm{H}]^{-} \\
390[\mathrm{M}+\mathrm{H}]^{+}, \\
388[\mathrm{M}-\mathrm{H}]^{-} \\
223[\mathrm{M}+\mathrm{H}]^{+} \\
245[\mathrm{M}+\mathrm{Na}]^{+}\end{array}$ & $\begin{array}{l}152 \\
201 \\
260 \\
114 \\
210 \\
144 \\
423 \\
406 \\
493 \\
230 \\
389 \\
222\end{array}$ & $\begin{array}{l}20 \mathrm{~mm} \text { zone of } \\
\text { inhibition against } \\
\text { MRSA A11; } 25 \mathrm{~mm} \\
\text { zone of inhibition } \\
\text { against MRSA A7 }\end{array}$ & $\begin{array}{l}\text { MW =152: Guanazolo, Orsellin- } \\
\text { aldehyde, } \\
\text { MY3-469, Xanthine. } \\
\text { MW = 260: Cyclo(L-Tyr-L-Pro), } \\
\text { VibrindoleA } \\
\text { MW = 114: 4-Hydroxy-5-methyl- } \\
\text { furan-3-one } \\
\text { MW = 210: 1-Methoxyphenazine, } \\
\text { 1-Acetyl- }- \text {-carboline } \\
\text { MW = 144: Pentenomycin I, 4- } \\
\text { Epipentenomycin I } \\
\text { MW = 423: Fibrostatin B, A9145 A, } \\
\text { 6-Amino-9 [(aminocarbonyl)amino]- } \\
\text { 1-(6-amino-9H-purin-9-yl)-1,5,6,7,8,9- } \\
\text { hexadeoxy-decafuranuronamide } \\
\text { MW = 389: Hatomamicin, SF-2809-I }\end{array}$ \\
\hline AFD8 & $\begin{array}{l}254 \mathrm{~nm} \\
366 \mathrm{~nm}\end{array}$ & $\begin{array}{l}4 \text { bands } \\
3 \text { bands }\end{array}$ & 4 blue bands & $\begin{array}{l}9.07 \\
13.42 \\
14.94 \\
15.58\end{array}$ & $\begin{array}{l}153[\mathrm{M}+\mathrm{H}]^{+} \\
151[\mathrm{M}-\mathrm{H}]^{-} \\
257[\mathrm{M}+\mathrm{H}]^{+} \\
255[\mathrm{M}-\mathrm{H}]^{-} \\
225[\mathrm{M}+\mathrm{H}]^{+} \\
181[\mathrm{M}+\mathrm{H}]^{+}\end{array}$ & $\begin{array}{l}152 \\
256 \\
224 \\
180\end{array}$ & $\begin{array}{l}12 \mathrm{~mm} \text { zone of } \\
\text { inhibition against } \\
\text { MRSA A } 12 ; 17 \mathrm{~mm} \\
\text { zone of inhibition } \\
\text { against MRSA A1 }\end{array}$ & $\begin{array}{l}\text { MW = 152: o Hydroxyphenylacetic } \\
\text { acid, BE-39907 A2 } \\
\text { MW = 256: Phenacein, Albonoursin, } \\
\text { N-Isobutyrylpyrrothine, 2,9- } \\
\text { Dihydroxyphenazine-1-carboxylic } \\
\text { acid }\end{array}$ \\
\hline AFD10 & $\begin{array}{l}254 \mathrm{~nm} \\
366 \mathrm{~nm}\end{array}$ & $\begin{array}{l}4 \text { bands } \\
1 \text { band }\end{array}$ & $\begin{array}{l}3 \text { yellow bands, } \\
2 \text { brown bands }\end{array}$ & $\begin{array}{l}9.90 \\
12.60 \\
15.61 \\
19.42\end{array}$ & $\begin{array}{l}211[\mathrm{M}+\mathrm{H}]^{+} \\
137[\mathrm{M}+\mathrm{H}]^{+} \\
135[\mathrm{M}-\mathrm{H}]^{-} \\
401[\mathrm{M}+\mathrm{H}]^{+} \\
399[\mathrm{M}-\mathrm{H}]^{-} \\
475[\mathrm{M}+\mathrm{H}]^{+} \\
473[\mathrm{M}-\mathrm{H}]^{-}\end{array}$ & $\begin{array}{l}210 \\
136 \\
400 \\
474\end{array}$ & $\begin{array}{l}17 \mathrm{~mm} \text { zone of } \\
\text { inhibition against } \\
\text { MRSA A7; } 20 \mathrm{~mm} \\
\text { zone of inhibition } \\
\text { against MRSA A2 }\end{array}$ & $\begin{array}{l}\text { MW =210: 1-Methoxyphenazine, } \\
\text { 1-Acetyl- } \beta \text {-carboline. } \\
\text { MW = 136: Pyrrole-3-yl-2- } \\
\text { propenamide, Anthranilamide, } \\
\text { Octalactin C. } \\
\text { MW = 400: Daunomycinol, } \\
\text { Furaquinocin G, Daidzein-7-a-L- } \\
\text { rhamnoside, } \\
\text { Oxopropaline-E, } 2 \text { 11-A. } \\
\text { MW = 474: N-Ethyloxytetracycline, } \\
\text { KS-619-1. }\end{array}$ \\
\hline AFD12 & $\begin{array}{l}254 \mathrm{~nm} \\
366 \mathrm{~nm}\end{array}$ & $\begin{array}{l}3 \text { bands } \\
2 \text { bands }\end{array}$ & $\begin{array}{l}1 \text { dark yellow band, } \\
1 \text { pink band, } \\
1 \text { green band }\end{array}$ & $\begin{array}{l}3.70 \\
4.36 \\
6.43 \\
12.50 \\
16.06\end{array}$ & $\begin{array}{l}160[\mathrm{M}+\mathrm{H}]^{+} \\
158[\mathrm{M}-\mathrm{H}]^{-} \\
110[\mathrm{M}-\mathrm{H}]^{-} \\
205[\mathrm{M}-\mathrm{H}]^{-} \\
137[\mathrm{M}+\mathrm{H}]^{+} \\
135[\mathrm{M}-\mathrm{H}]^{-} \\
211[\mathrm{M}+\mathrm{H}]^{+}\end{array}$ & $\begin{array}{l}- \\
159 \\
111 \\
206 \\
136 \\
210\end{array}$ & $\begin{array}{l}11 \mathrm{~mm} \text { zone of } \\
\text { inhibition against } \\
\text { MRSA A7; } 15 \mathrm{~mm} \\
\text { zone of inhibition } \\
\text { against MRSA A5 }\end{array}$ & $\begin{array}{l}\text { MW=159: 4-(Hydroxymethyl) } \\
\text { quinolone, Quinazolinamine } \\
\text { MW=136: Pyrrole-3-yl-2- } \\
\text { propenamide, Anthranilamide, } \\
\text { Octalactin C. } \\
\text { MW=210: Nikkomycin E, (4R)- } \\
\text { Thiolactomycin, Cyanomycin, } \\
\text { 2-Amino-4-hydroxy-3-methyl-4- } \\
\text { (3-pyridyl)butanoic acid. }\end{array}$ \\
\hline
\end{tabular}


Table 5 HPLC-MS analyses of the active desert actinobacterial strain (Continued)

\begin{tabular}{|c|c|c|c|c|c|c|c|}
\hline \multirow[t]{2}{*}{ Strains } & \multicolumn{2}{|c|}{$\begin{array}{l}\text { Thin Layer Chromatography (TLC) } \\
\text { Profile }\end{array}$} & \multirow{2}{*}{$\begin{array}{l}\text { HPLC- } \\
\text { Retention } \\
\text { time }\left(t_{R} / \text { min }\right)\end{array}$} & \multirow[t]{2}{*}{$\begin{array}{l}(+) \text { and }(-)- \\
\text { ESI-MS: }(m / z)\end{array}$} & \multirow[t]{2}{*}{$\begin{array}{l}\text { Molecular } \\
\text { Weights }\end{array}$} & \multirow[t]{2}{*}{$\begin{array}{l}\text { Activity against } \\
\text { MRSA }\end{array}$} & \multirow{2}{*}{$\begin{array}{l}\text { Suggested Streptomyces metabolites } \\
\text { from AntiBase } 2017 \\
\text { (Additional files } 15 \text { and 20) }\end{array}$} \\
\hline & $\begin{array}{l}\text { UV } \\
\text { Visualization }\end{array}$ & $\begin{array}{l}\text { Staining with } \\
\text { Anisaldehyde/ } / \mathrm{H}_{2} \mathrm{SO}_{4}\end{array}$ & & & & & \\
\hline AFD26 & $\begin{array}{l}254 \mathrm{~nm} \quad 4 \text { bands } \\
366 \mathrm{~nm} \quad 2 \text { bands }\end{array}$ & $\begin{array}{l}1 \text { brown bands, } \\
1 \text { purple band, } \\
1 \text { light blue band, } \\
1 \text { greenish blue band }\end{array}$ & $\begin{array}{l}.48 \\
6.32 \\
6.38 \\
9.49 \\
10.85 \\
12.23 \\
17.43\end{array}$ & $\begin{array}{l}1052[\mathrm{M}+\mathrm{H}]^{+} ? ? \\
113[\mathrm{M}+\mathrm{H}]^{+}, \\
111[\mathrm{M}-\mathrm{H}]^{-} \\
164[\mathrm{M}+\mathrm{H}]^{+}, \\
162[\mathrm{M}-\mathrm{H}]^{-} \\
164[\mathrm{M}+\mathrm{H}]^{+}, \\
162[\mathrm{M}-\mathrm{H}]^{-} \\
164[\mathrm{M}+\mathrm{H}]^{+} \\
162[\mathrm{M}-\mathrm{H}]^{-} \\
317[\mathrm{M}+\mathrm{H}]^{+} \\
391[\mathrm{M}+\mathrm{H}]^{+}\end{array}$ & $\begin{array}{l}112 \\
163 \\
163 \\
163 \\
316 \\
390\end{array}$ & $\begin{array}{l}10 \mathrm{~mm} \text { zone of } \\
\text { inhibition against } \\
\text { MRSA A1; } 15 \mathrm{~mm} \\
\text { zone of inhibition } \\
\text { against MRSA A7 }\end{array}$ & $\begin{array}{l}\text { MW = 112: Emimycin, 3,5-Dimethyl- } \\
\text { 3-oxol-2-on, Uracil, Enimycin. } \\
\text { MW = 163: L- } \beta \text {-(3-Hydroxyureido)- } \\
\text { alanine, Homoalanosine, } \beta \text { - } \\
\text { Phenylethylacetamide, 2-N-Hydroxy- } \\
\text { 3,4-dihydroisoquinoline-1-one, } \\
\text { Streptazone D, 2-Amino-4-hydroxy- } \\
\text { pterin, 6-Hydroxy-isatin, } \\
\text { Dihydroabikoviromycin, 3-Nitro- } \\
\text { 1H-indazole, Kitasatodine } \\
\text { MW = 316: 17927-D, Boxazomycin } \\
\text { A, } 1 \text { Isobutyroxymethyl cyclohex- } \\
\text { 1(6)-ene-2,3,4,5-tetrol-2-isobutyrate. } \\
\text { MW = 390: SF-2330, Arizonin C3. }\end{array}$ \\
\hline
\end{tabular}

For details, see Supplementary Information (Figure S3-S20)

scope and environmental distribution. Harsh conditions like dryness, extreme temperatures and alkalinity directed to the isolation of very resistant actinomycetes from untapped environments like deserts, caves etc. Different useful strategies are required to exploit these habitats for the discovery of stress tolerant bacterial species [32].
In the present study 110 actinobacterial strains were isolated from the Cholistan desert. The polyphasic taxonomic characterization including morphological, microscopic, biochemical and physiological characteristics and 16S rRNA gene sequence analysis suggested that these isolates belong to different actinobacterial genera and species. In biochemical characterization it was found that these were able to

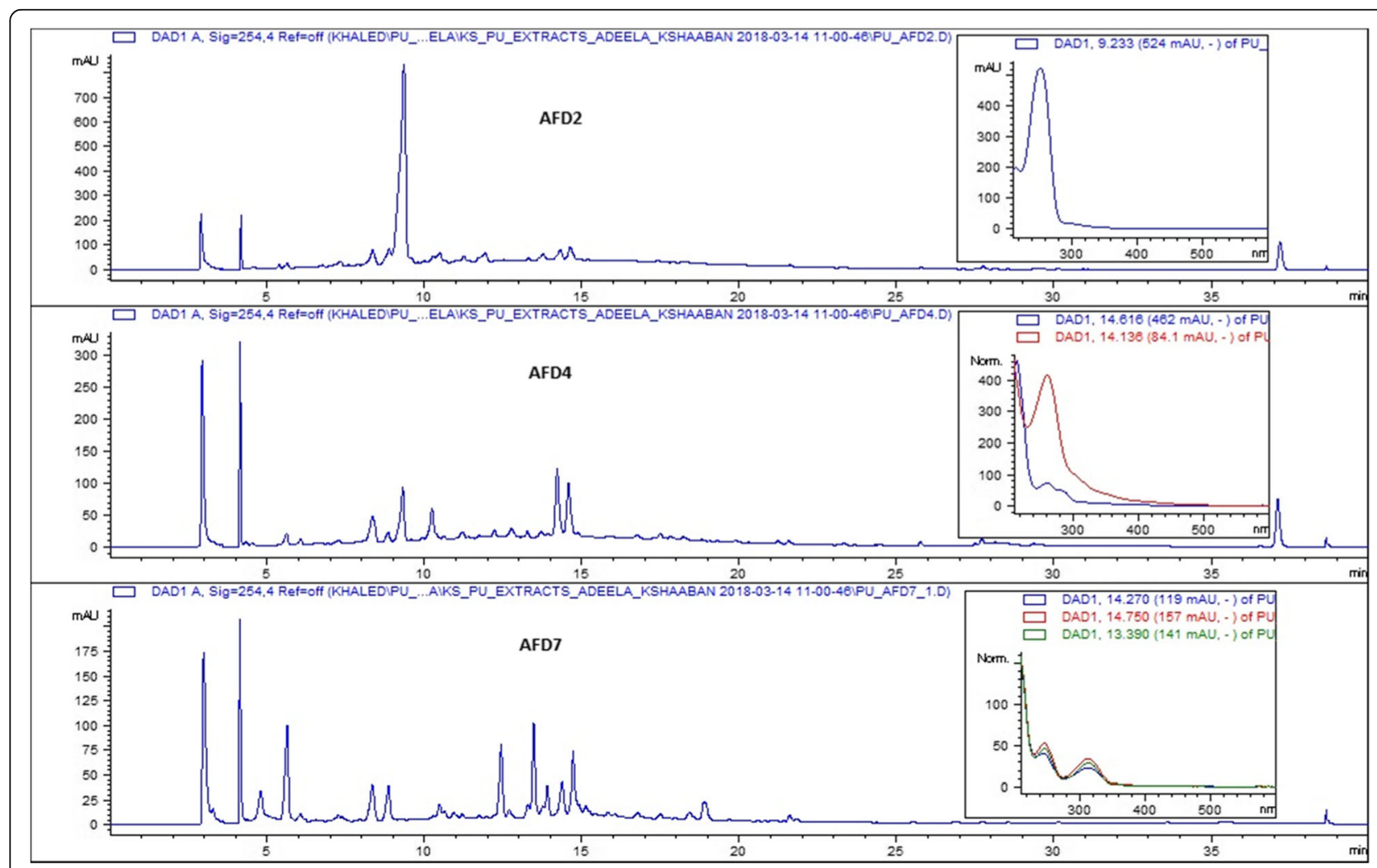

Fig. $4 \mathrm{HPLC/UV}$ analyses of the crude extracts produced by the actinobacterial strains AFD2, AFD4 and AFD7 (Detection wavelength $254 \mathrm{~nm}$ ). For the full-expended versions of this figure, see Supplementary Information, Additional files 6, 8 and 7 (Figure S3, S5 and S7) 
produce melanin pigment which may be an avoidance strategy to the desiccation and intense radiation, as described by many researchers like Bull and Asenjo [33]. They reported that the actinobacteria living in extreme conditions can be metabolically functional and they may not be considered as dormant. Another very important feature for the identification of actinomycetes especially Streptomyces is the determination of utilization of different sugars as a source of carbon. For this purpose these strains were tested for their ability to utilize 8 different sugars (D-fructose, D-glucose, D-galactose, L-arabinose, D-mannitol, sucrose, inositol and mannose). It was found that most of the strains used mainly the glucose as the carbon source, however fructose and sucrose were the next sugars which were used most frequently, these results are comparable with the findings of Aftab et al. [34].

The actinobacterial spores have the capability to germinate in very low available water environments and it enables them to adapt to drought conditions. Our major focus has been on the spore forming actinobacterial diversity, so scanning electron microscopic (SEM) analysis of the aerial spores and substrate mycelium of some of the representative strains showed extensive substrate mycelium and interlocking patterns of the cells, which might be due to the high temperature, high salinity, and radiations effect $[10$, 35]. A variety of shapes of spores were observed using different magnifications ( $5 \mathrm{kx}, 10 \mathrm{kx}, 15 \mathrm{kx}, 20 \mathrm{kx}, 25 \mathrm{kx}, 40$ $\mathrm{kx}$ and $50 \mathrm{kx}$ ), which were arranged in the form of chains and clusters showing various stages of spore development (Fig. 2). The comparison of the spores arrangement and shapes with the descriptions given in Bergey's manual of systematic bacteriology $[29,30]$ indicated the major resemblance of these strains with different Streptomyces species.

The 16S rRNA gene sequencing and BLAST search via EzTaxon server and subsequent phylogenetic analysis gave the in-depth insights into the actinobacterial diversity in this extreme ecological niche. Mainly the strains belonged to three different families of the order Actinomycetales, including the family Streptomycetaceae, the family Pseudonocardiaceae and the family Micrococcaceae. In most of the cases strains shared $>99 \%$ genetic similarity with the Streptomyces type strains, while 5 of the strains including AFD6, AFD13, AFD23, AFD26 and AFD29 showed <99\% similarity, usually in the range of $97-98 \%$ (Fig. 3). This shows that these 5 strains could be different taxon or new Streptomyces species; however the complete $16 \mathrm{~S}$ rRNA gene sequences and other relevant genetic approaches such as DNA-DNA hybridization with the type strain etc can further unveil their exact taxonomic status. Okoro et al. [36] reported that majority of the isolates from the soil of Atacama Desert located in south America belonged to the genera Amycolatopsis, Lechevalieria and Streptomyces.
The second major goal in this study was to detect and obtain the actinobacterial strains which exhibit potent activity against MRSA (methicillin resistant Staphylococcus aureus). MRSA has been designated as the superbug due to its resistance to almost all the known antibiotic classes. In this scenario activity against MRSA is extremely needed to search the new antimicrobial drug candidates. The actinobacterial strains from this unique ecological environment exhibit remarkable activity against MRSA test strains. Among the 110 strains, in initial screens by agar plug method 30 strains were detected to be active against MRSA. While, further screening through well diffusion method revealed the potent inhibitory activity of these strains against all the MRSA strains. Especially, the strain AFD2 Streptomyces pseudogriseolus showed $32 \mathrm{~mm}$ zone of inhibition against MRSA. In general, the zone of inhibition in the range of 9-32 $\mathrm{mm}$ was observed which is comparable to the findings of Nithya et al. [37], who reported the inhibition of MRSA by desert actinomycetes isolated from Saudi Arabian desert.

The chemical profiling of the crude extracts of these actinobacterial strains showed that they produce compounds belonging to different structural classes, as indicated by colored bands on TLC after staining with anisaldehyde $/ \mathrm{H}_{2} \mathrm{SO}_{4}$. For instance, the development of yellow spots indicated the production of actinomycin like compounds, pink spots indicated quinolone like compounds, blue spots were indicative of peptide like fractions, however the peptides are needed to confirm by staining with iodine vapors etc. The greenish spots are usually shown by allylic alcohols, red spots for amines, aldehydes, ketones, carbohydrates and esters (alkyl phthalates) and violet spots for phenols etc. The HPLC/UV chromatograms exhibited a comparative account of the metabolic capability of the isolated actinobacterial strains, as varied number of peaks (up to 7-8 peaks) at different retention times $\left(t_{R}\right)$ were observed in the methanolic extracts. This shows that these actinobacterial strains are capable to produce variety of different compounds at the same time with different concentrations. The LC-MS analysis of the strains with prominent activity against MRSA indicated that these actinobacterial strains produce low molecular weight compounds usually $<500 \mathrm{Da}$. This shows that these active components can be potential antibiotic candidates because the higher molecular weight compounds usually show various cytotoxic effects in the subsequent drug development process. The metabolic profiles of the methanolic extracts of these actinobacterial strains are comparable with those reported by Taddei et al. [38] and Anwar et al. [17], where 5-8 major metabolites has been detected in the extract of one strain.

The comparison of the biological activity and chemical profile of the compounds produced by these strains with those of reported in AntiBase provides deeper insights in to the chemical nature/identity and structural diversity of 
these active compounds. The AntiBase [28] is a largest and most authentic database with more than 40,000 natural compounds produced by different microorganisms especially by Streptomyces. For instance, the strain AFD2 showed the production of a compound which had the close match with the antibiotic Emimycin and Triacsin. In the same manner, the strain AFD4 exhibited the production of different compounds with close matches in database with the antibiotics like 1-Methoxyphenazine and Pyrrole-3-yl-2-propenamide. Similarly, the strain AFD7 exhibited the production of various compounds with close matches with antibiotic compounds such as, Xanthine, Pentenomycin I and Fibrostatin B. The strain AFD8 exhibited the presence of different compounds which had the close matches with the compounds in the AntiBase e.g. o-Hydroxyphenylacetic acid and Phenacein. The strain AFD10 showed the production of different compounds which had the close match with the different antibiotic compounds in the database including Anthranilamide and 1-Methoxyphenazine. The strain AFD12 also exhibited the production of different active components which showed the closest matches with 4-(Hydroxymethyl) quinolone and Nikkomycin E. The strain AFD26 exhibited the production of various antibiotic components which had the close matches with Emimycin, Dihydroabikoviromycin and Boxazomycin A (Table 5). The results showed that the diverse spore forming actinobacterial strains are present in this harsh ecological niche and most of them are capable of producing variety of structurally diverse compounds.

\section{Conclusions}

The study revealed that the Cholistan desert in Pakistan harbors an immense and untapped diversity of culturable spore forming actinobacteria with valuable antimicrobial potential against MRSA. The most frequently isolated strains in this study belong to the family Streptomycetaceae, and 27 different species of genus Streptomyces were identified. The two strains were identified to be the members of different families, such as strain AFD18 Saccharothrix xinjiangensis belongs to the family Pseudonocardiaceae and the strain AFD22 Arthrobacter sp. belongs to the family Micrococcaceae. Our findings based on in-depth chemical profiling confirms that most of the strains from this extreme and harsh environment are capable of producing variety of low molecular weight secondary metabolites belonging to different antibiotics structural classes, which should be explored further for new antimicrobial drug candidates.

\section{Additional files}

Additional file 1: Isolation media used for the Actinobacterial Diversity (PDF $279 \mathrm{~kb}$ )
Additional file 2: Table S1. Primary screening of all the isolated desert actinobacterial strains against MRSA by agar plug method (PDF $201 \mathrm{~kb}$ )

Additional file 3: Table S2. Microbiological and biochemical characteristics of Cholistan desert actinobacterial strains (PDF $309 \mathrm{~kb}$ )

Additional file 4: Figure S1. Morphological appearance of selected Cholistan desert actinobacterial strains on GYM agar (A) strain AFD2 Streptomyces pseudogriseolus (B) strain AFD3 Streptomyces canarius (C) strain AFD6 Streptomyces fradiae (D) strain AFD13 Streptomyces roseofulvus (E) strain AFD16 Streptomyces pratensis (F) strain AFD10 Streptomyces puniceus (PDF $250 \mathrm{~kb}$ )

Additional file 5: Figure S2. Antibacterial activity of the selected actinobacterial strains against MRSA isolates: (A, B) Zone of inhibition in agar plug method, (C, D) zone of inhibition in well method, (E) different bands of crude extracts of actinomycete isolates under UV at $366 \mathrm{~nm}$ (F) at $254 \mathrm{~nm}$ wavelength. (PDF $232 \mathrm{~kb}$ )

Additional file 6: Figure S3. HPLC/UV analyses of AFD2 crude extract. HPLC-conditions: Detection wavelength $254 \mathrm{~nm}$; solvent $\mathrm{A}: \mathrm{H}_{2} \mathrm{O} / 0.1 \%$ TFA; solvent B: acetonitrile; flow rate: $1.0 \mathrm{~mL} \mathrm{~min}^{-1} ; 0-30 \mathrm{~min}, 95-0 \% \mathrm{~A}$ (linear gradient); 30-35 min 0\% A; 35-36 min 0-95\% A (linear gradient); 36-40 min 95\% A. (PDF $224 \mathrm{~kb})$

Additional file 7 : Figure S7. HPLC/UV analyses of AFD7 crude extract. HPLC-conditions: Detection wavelength $254 \mathrm{~nm}$; solvent $\mathrm{A}: \mathrm{H}_{2} \mathrm{O} / 0.1 \%$ TFA; solvent B: acetonitrile; flow rate: $1.0 \mathrm{~mL} \mathrm{~min}^{-1} ; 0-30 \mathrm{~min}, 95-0 \% \mathrm{~A}$ (linear gradient); 30-35 min 0\% A; 35-36 min 0-95\% A (linear gradient); 36-40 min 95\% A. (PDF $246 \mathrm{~kb}$ )

Additional file 8: Figure S5. HPLC/UV analyses of AFD4 crude extract. HPLC-conditions: Detection wavelength $254 \mathrm{~nm}$; solvent A: $\mathrm{H}_{2} \mathrm{O} / 0.1 \%$ TFA; solvent B: acetonitrile; flow rate: $1.0 \mathrm{~mL} \mathrm{~min}^{-1} ; 0-30 \mathrm{~min}, 95-0 \% \mathrm{~A}$ (linear gradient); 30-35 min 0\% A; 35-36 min 0-95\% A (linear gradient); 36-40 min 95\% A. (PDF $59 \mathrm{~kb}$ )

Additional file 9 : Figure S9. HPLC/UV analyses of AFD8 crude extract. HPLC-conditions: Detection wavelength $254 \mathrm{~nm}$; solvent $\mathrm{A}: \mathrm{H}_{2} \mathrm{O} / 0.1 \%$ TFA; solvent B: acetonitrile; flow rate: $1.0 \mathrm{~mL} \mathrm{~min}^{-1}$; 0-30 min, $95-0 \% \mathrm{~A}$ (linear gradient); 30-35 min 0\% A; 35-36 min 0-95\% A (linear gradient); 36-40 min 95\% A. (PDF $63 \mathrm{~kb}$ )

Additional file 10: Figure S11. HPLC/UV analyses of AFD10 crude extract. HPLC-conditions: Detection wavelength $254 \mathrm{~nm}$; solvent A: $\mathrm{H}_{2} \mathrm{O}$ / $0.1 \%$ TFA; solvent $B$ : acetonitrile; flow rate: $1.0 \mathrm{~mL} \mathrm{~min}^{-1} ; 0-30 \mathrm{~min}, 95-0 \%$ A (linear gradient); 30-35 min 0\% A; 35-36 min 0-95\% A (linear gradient); 36-40 min 95\% A. (PDF $346 \mathrm{~kb}$ )

Additional file 11: Figure S13. HPLC/UV analyses of AFD12 crude extract. HPLC-conditions: Detection wavelength $254 \mathrm{~nm}$; solvent $\mathrm{A}: \mathrm{H}_{2} \mathrm{O}$ / $0.1 \%$ TFA; solvent B: acetonitrile; flow rate: $1.0 \mathrm{~mL} \mathrm{~min}^{-1} ; 0-30 \mathrm{~min}, 95-0 \%$ A (linear gradient); 30-35 min 0\% A; 35-36 min 0-95\% A (linear gradient); 36-40 min 95\% A. (PDF $231 \mathrm{~kb}$ )

Additional file 12 : Figure S15. HPLC/UV analyses of AFD14 crude extract. HPLC-conditions: Detection wavelength $254 \mathrm{~nm}$; solvent $\mathrm{A}: \mathrm{H}_{2} \mathrm{O}$ / $0.1 \%$ TFA; solvent B: acetonitrile; flow rate: $1.0 \mathrm{~mL} \mathrm{~min}^{-1} ; 0-30 \mathrm{~min}, 95-0 \%$ A (linear gradient); 30-35 min 0\% A; 35-36 min 0-95\% A (linear gradient): 36-40 min 95\% A. (PDF $242 \mathrm{~kb}$ )

Additional file 13 : Figure S17. HPLC/UV analyses of AFD26 crude extract. HPLC-conditions: Detection wavelength $254 \mathrm{~nm}$; solvent $\mathrm{A}: \mathrm{H}_{2} \mathrm{O}$ / $0.1 \%$ TFA; solvent B: acetonitrile; flow rate: $1.0 \mathrm{~mL} \mathrm{~min}^{-1} ; 0-30 \mathrm{~min}, 95-0 \%$ A (linear gradient); 30-35 min 0\% A; 35-36 min 0-95\% A (linear gradient); 36-40 min 95\% A. (PDF $233 \mathrm{~kb}$ )

Additional file 14: Figure S4. HPLC/MS analyses of AFD2 crude extract. HPLC-conditions: Detection wavelength $254 \mathrm{~nm}$; solvent $\mathrm{A}: \mathrm{H}_{2} \mathrm{O} / 0.1 \%$ Formic acid, solvent $\mathrm{B}$ : $\mathrm{CH}_{3} \mathrm{CN} / 0.1 \%$ Formic acid; flow rate: $0.5 \mathrm{~mL} \mathrm{~min}^{-1}$; $0-4$ $\min , 10 \%$ B; 4-22 min, $10-100 \%$ B; 22-27 min, 100\% B; 27-29 min, 100-10\% B; 29-30 min, 10\% B. (MW = Molecular Weight). (PDF 313 kb)

Additional file 15: Figure S19. Chemical structures of the suggested Streptomyces metabolites based on HPLC-UVNis and LC-MS analyses and by searching in AntiBase 2017. (PDF $251 \mathrm{~kb}$ )

Additional file 16: Figure S6. HPLC/MS analyses of AFD4 crude extract. HPLC-conditions: Detection wavelength 254 nm; solvent A: $\mathrm{H}_{2} \mathrm{O} / 0.1 \%$ 
Formic acid, solvent $\mathrm{B}: \mathrm{CH}_{3} \mathrm{CN} / 0.1 \%$ Formic acid; flow rate: $0.5 \mathrm{~mL} \mathrm{~min}^{-1}$ 0-4 min, 10\% B; 4-22 min, 10-100\% B; 22-27 min, 100\% B; 27-29 min, 100-10\% B; 29-30 min, 10\% B. (MW = Molecular Weight). (PDF $421 \mathrm{~kb})$

Additional file 17 : Figure S8. HPLC/MS analyses of AFD7 crude extract. HPLC-conditions: Detection wavelength $254 \mathrm{~nm}$; solvent A: $\mathrm{H}_{2} \mathrm{O} / 0.1 \%$ Formic acid, solvent $\mathrm{B}: \mathrm{CH}_{3} \mathrm{CN} / 0.1 \%$ Formic acid; flow rate: $0.5 \mathrm{~mL} \mathrm{~min}^{-1} ; 0-4 \mathrm{~min}, 10 \% \mathrm{~B} ; 4-22 \mathrm{~min}, 10-100 \% \mathrm{~B} ; 22-27 \mathrm{~min}, 100 \%$ B; 27-29 min, 100-10\% B; 29-30 min, 10\% B. (MW = Molecular Weight). (PDF $409 \mathrm{~kb}$ )

Additional file 18: Figure S10. HPLC/MS analyses of AFD8 crude extract. HPLC-conditions: Detection wavelength $254 \mathrm{~nm}$; solvent $\mathrm{A}: \mathrm{H}_{2} \mathrm{O} / 0.1 \%$ Formic acid, solvent $\mathrm{B}: \mathrm{CH}_{3} \mathrm{CN} / 0.1 \%$ Formic acid; flow rate: $0.5 \mathrm{~mL} \mathrm{~min}^{-1} ; 0-4$ min, 10\% B; 4-22 min, 10-100\% B; 22-27 min, 100\% B; 27-29 min, 100-10\% B; 29-30 min, 10\% B. (MW = Molecular Weight) (PDF 385 kb)

Additional file 19: Figure S12. HPLC/MS analyses of AFD10 crude extract. HPLC-conditions: Detection wavelength $254 \mathrm{~nm}$; solvent A: $\mathrm{H}_{2} \mathrm{O} / 0.1 \%$ Formic acid, solvent $\mathrm{B}: \mathrm{CH}_{3} \mathrm{CN} / 0.1 \%$ Formic acid; flow rate: $0.5 \mathrm{~mL} \mathrm{~min}^{-1} ; 0-4 \mathrm{~min}, 10 \% \mathrm{~B} ; 4-22 \mathrm{~min}, 10-100 \% \mathrm{~B} ; 22-27 \mathrm{~min}, 100 \%$ B; 27-29 min, 100-10\% B; 29-30 min, 10\% B. (MW = Molecular Weight) (PDF $434 \mathrm{~kb}$ )

Additional file 20: Figure S20. Chemical structures of the suggested Streptomyces metabolites based on HPLC-UVN Nis and LC-MS analyses and by searching in AntiBase 2017. (PDF $400 \mathrm{~kb}$ )

Additional file 21 : Figure S14. HPLC/MS analyses of AFD12 crude extract. HPLC-conditions: Detection wavelength $254 \mathrm{~nm}$; solvent A: $\mathrm{H}_{2} \mathrm{O} / 0.1 \%$ Formic acid, solvent $\mathrm{B}: \mathrm{CH}_{3} \mathrm{CN} / 0.1 \%$ Formic acid; flow rate: $0.5 \mathrm{~mL} \mathrm{~min}^{-1}$; 0-4 min, 10\% B; 4-22 min, $10-100 \%$ B; $22-27 \mathrm{~min}, 100 \%$ B; 27-29 min, $100-10 \%$ B; 29-30 min, 10\% B. (MW = Molecular Weight) (PDF $431 \mathrm{~kb}$ )

Additional file 22 : Figure S16. HPLC/MS analyses of AFD14 crude extract. HPLC-conditions: Detection wavelength $254 \mathrm{~nm}$; solvent $\mathrm{A}$ : $\mathrm{H}_{2} \mathrm{O}$ / $0.1 \%$ Formic acid, solvent $\mathrm{B}: \mathrm{CH}_{3} \mathrm{CN} / 0.1 \%$ Formic acid; flow rate: $0.5 \mathrm{~mL}$ $\min ^{-1}$; 0-4 min, 10\% B; 4-22 min, 10-100\% B; 22-27 min, 100\% B; 27-29 min, $100-10 \%$ B; $29-30$ min, 10\% B. No clear mass was detected for this extract, howver it is very intersting based on the HPLC-UVNis profile (Fig. S17). (PDF $334 \mathrm{~kb}$ )

Additional file 23: Figure S18. HPLC/MS analyses of AFD26 crude extract. HPLC-conditions: Detection wavelength $254 \mathrm{~nm}$; solvent A: $\mathrm{H}_{2} \mathrm{O} / 0.1 \%$ Formic acid, solvent $\mathrm{B}: \mathrm{CH}_{3} \mathrm{CN} / 0.1 \%$ Formic acid; flow rate: $0.5 \mathrm{~mL} \mathrm{~min}^{-1}$; 0-4 min, 10\% B; 4-22 min, 10-100\% B; 22-27 min, 100\% B; 27-29 min, 100-10\% B; 29-30 min, 10\% B. (MW = Molecular Weight). (PDF $410 \mathrm{~kb}$ )

\section{Abbreviations}

AMR: Antimicrobial Resistance; BLAST: Basic Local Alignment Search Tool; bp: Base pair; C: Citrate; CLSI: Clinical and Laboratory Standards Institute; DF: D-Fructose; DG: D-Glucose; DGL: D-Galactose; DM: D-Mannitol; DNA: Deoxyribonucleic acid; DNase: Deoxyribonuclease; GIS: Geographic Information System; GYM: Glucose-yeast extract-malt extract; HPLC-UV/ Vis: High Performance Liquid Chromatography-Ultraviolet/Visible; I: Inositol; ISP: International Streptomyces Project; Km: Kilometers; LA: L-Arabinose; LC-MS: Liquid Chromatography- Mass Spectrometry; M: Mannose; M: Melonate; MEGA6: Molecular Evolutionary Genetics Analysis Version 6; MH: Muller Hinton; mm: Milimeter; MMG: Microbiology and Molecular Genetics; MP: Melanin Production; MRSA: Methicillin Resistant Staphylococcus aureus; MW: Molecular Weight; NCBI: National Center for Biotechnology Information; OTUs: Operational Taxonomic Units; PCR: Polymerase Chain Reaction; rRNA: Ribosomal Ribonucleic Acid; S: Sucrose; S. aureus: Staphylococcus aureus; SE: Secondary Electron; SEM: Scanning Electron Microscopy; TLC: Thin Layer Chromatography; $t_{R}$ : Retention Time; UV: Ultraviolet

\section{Acknowledgments}

Not applicable.

\section{Funding}

This work was supported by the grant from Higher Education Commission (HEC) Pakistan (Grant No. PIN: 112-31652-2BM1-172, and HEC-NRPU Project
2121). This work was also supported by National Institutes of Health grant R24 OD21479 (JST), The University of Kentucky, College of Pharmacy and the National Center for Advancing Translational Sciences (UL1TR001998 and UL1TR000117). The grants PIN: 112-31652-2BM1-172, and HEC-NRPU Project 2121 , provided the support in terms of student's stipend and experimental design, travel cost for sample collection, research supplies, reagents, DNA sequencing cost, data analysis and writing the paper. Grants R24 OD21479 (JST), UL1TR001998 and UL1TR000117 supported, in part, personnel and reagents associated with chemical screening, analytical methods and data analysis.

\section{Availability of data and materials}

All data analyzed and generated in this study are presented in the manuscript and additional files are submitted in the form of additional file in the editorial manager.

\section{Permission required for collection of soil samples}

The soil samples were collected and no permission was required because these were not collected from anyone's property.

\section{Authors' contributions}

A.F. executed the experiments and wrote the first draft of the manuscript; U.A. helped in experiments and in data analysis; K.A.S. and J.S.T. contributed to analytical support (HPLC/UV and HPLC/MS analysis), data analysis and consultation; I.S. overall supervised the study and finalized the draft of the manuscript.

\section{Ethics approval and consent to participate}

Not applicable.

\section{Consent for publication}

Not applicable.

\section{Competing interests}

The authors declare that they have no competing interests.

\section{Publisher's Note}

Springer Nature remains neutral with regard to jurisdictional claims in published maps and institutional affiliations.

\section{Author details}

'Department of Microbiology and Molecular Genetics (MMG), University of the Punjab, Quaid-e-Azam Campus, Lahore 54590, Pakistan. ${ }^{2}$ Center for Pharmaceutical Research and Innovation, College of Pharmacy, University of Kentucky, Lexington, KY 40536, USA. ${ }^{3}$ Department of Pharmaceutical Sciences, College of Pharmacy, University of Kentucky, Lexington, KY 40536, USA.

Received: 10 September 2018 Accepted: 8 February 2019

Published online: 22 February 2019

\section{References}

1. Islam ZU, Iqbal J, Khan JA, Qazi WA. Paleochannel delineation using Landsat $8 \mathrm{OLI}$ and Envisat ASAR image fusion techniques in Cholistan desert Pakistan. J Appl Remote Sens. 2016;10:046001.

2. Akbar G, Khan TN, Arshad M. Cholistan desert Pakistan range lands. Sci Vis. 1996;5:77-85.

3. Arshad M, Ashraf MY, Ahmad M, Zaman F. Morphogenetic variability potential of Cenchrusciliaris L., from Cholistan Desert, Pakistan. Pak J Bot. 2007;39:1481-8.

4. Maldonado LA, Stach JE, Pathom-Aree W, Ward AC, Bull AT, Goodfellow M Diversity of cultivable actinobacteria in geographically widespread marine sediments. Antonie Van Leeuwenhoek. 2005;87:11-8.

5. Singh S, Young K, Silver L. What is an "ideal" antibiotic? Discovery, challenges and path forward. Biochem Pharmacol. 2017;133:63-73.

6. Demain AL, Sanchez S. The need for new antibiotics. In: Sanchez S, Demain AL, editors. Antibiotics: Current Innovations and Future Trends. Norfolk: Caister Academic Press; 2015. p. 65-82.

7. Harwani D. Biodiversity of rare thermophilic actinomycetes in the great Indian Thar desert: an overview. Indo Am J Pharm Res. 2013;3:934-9. 
8. Thumar JT, Dhulia K, Singh SP. Isolation and partial purification of an antimicrobial agent from halotolerant, alkaliphilic Streptomyces aburaviensis strain Kut-8. World J Microbiol Biotechnol. 2010;26:2081-7.

9. Golding CG, Lamboo LL, Beniac DR, Booth TF. The scanning electron microscope in microbiology and diagnosis of infectious disease. Sci Rep. 2016:6:26516.

10. Williams ST, Davies FL. Use of a scanning electron microscope for the examination of actinomycetes. J Gen Microbiology. 1967;48(2):171-7.

11. Beniac DR, Siemens CG, Wright CJ, Booth TF. A filtration based technique for simultaneous SEM and TEM sample preparation for the rapid detection of pathogens. Viruses. 2014. https://doi.org/10.3390/v6093458.

12. Fatima A, Riaz S, Sajid I. Anti-MRSA potential and metabolic fingerprinting of actinobacteria from Cholistan desert Pakistan. Trop J Pharm Res. 2018;17(10):2037-46.

13. Hayakawa $\mathrm{M}$, Nonomura $\mathrm{H}$. A new method for the intensive isolation of actinomycetes from soil. Actinomycetol. 1989;3:95-104.

14. Shirling ET, Gottlieb D. Methods for characterisation of Streptomyces species1. Int J Syst Evol Microbiol. 1966;16:313-40.

15. Fguira LF, Fotso S, Ameur-Mehdi RB, Mellouli L, Laatsch H. Purification and structure elucidation of antifungal and antibacterial activities of newly isolated Streptomyces sp strain US 80. Res Microbiol. 2005;156:341-7.

16. Bensultana A, Ouhdouch Y, Hassani L, Mezrioui NE, Rafouk L. Isolation and characterisation of wastewater sand filter actinomycetes. World J Microbiol Biotechnol. 2010;26:481-7.

17. Anwar S, Ali B, Qamar F, Sajid I. Insecticidal activity of actinomycetes isolated from salt range, Pakistan against mosquitoes and red flour beetle. Pak J Zool. 2014;46:83-92.

18. Innis MA, Gelfand DH. Optimization of PCRs. In: Innis MA, Gelfand DH, Sninsky JJ, White TJ, editors. PCR protocols: a guide to methods and applications. San Diego: Academic Press Inc; 1990. p. 3-12.

19. NCBI Database https://blast.ncbi.nlm.nih.gov. Accessed 22nd December, 2017.

20. EzBioCloud Server. https://www.ezbiocloud.net/. Accessed 10th June, 2018

21. Felsenstein J. Confidence limits on phylogenies: an approach using the bootstrap. Evolution. 1985;39:783-91.

22. Saitou N, Nei M. The neighbor-joining method: a new method for reconstructing phylogenetic trees. Mol Biol Evol. 1987;4:406-25.

23. Tamura K, Nei M, Kumar S. Prospects for inferring very large phylogenies by using the neighbor-joining method. Proc Natl Acad Sci U S A. 2004;101:11030-5.

24. Tamura K, Stecher G, Peterson D, Filipski A, Kumar S. MEGA6: molecular evolutionary genetics analysis version 6.0. Mol Biol Evol. 2013;30:2725-9.

25. Cavaletti L, Monciardini P, Bamonte R, Schumann P, Rohde M, Sosio M, Donadio S. New lineage of filamentous, spore-forming, gram-positive bacteria from soil. Appl Environ Microbiol. 2006. https://doi.org/10.1128/ AEM.00132-06.

26. Cavaleri J, Rankin D, Harbeck J, Sautter LR, McCarter SY, Sharp SE, Ortez HJ, Spiegel AC. 2005. Manual of antimicrobial susceptibility testing. American Society for Microbiology., Washington. Seattle. 2005;12:53-42.

27. Sajid I, Yao CBFF, Shaaban KA, Hasnain S, Laatsch H. Antifungal and antibacterial activities of indigenous Streptomyces isolates from saline farmlands: prescreening, ribotyping and metabolic diversity. World $J$ Microbiol Biotechnol. 2009;25:601.

28. Laatsch H (2017) AntiBase. The Natural Compound Identifier Wiley-Vch.

29. Parte A, Whitman W, Goodfellow M, Kämpfer P, Busse HJ, Trujillo ME, Suzuki Kl, Ludwig W, Whitman WB. The Actinobacteria, Bergey's manual of systematic bacteriology. New York: Springer; 2012.

30. Lechevalier HA. A practical guide to generic identification of actinomycetes. In: Williams ST, Sharpe ME, Holt JG, editors. Bergey's manual of systematic bacteriology. Baltimore: Williams \& Wilkins; 1989. p. 2344-7.

31. Różylo JK, Janicka M, Siembida R. Advantages of TLC as a pilot technique for HPLC. J Liq Chromatogr Relat Technol. 1994;17:3641-53.

32. Ding D, Chen G, Wang B, Wang Q, Liu D, Peng M, Shi P. Culturable actinomycetes from desert ecosystem in north east of Qinghai-Tibet plateau. Ann Microbiol. 2013a;63:259-66.

33. Bull AT, Asenjo JA. Microbiology of hyper arid environments: recent insights from the Atacama Desert, Chile. Antonie Van Leeuwenhoek. 2013. https:// doi.org/10.1007/s10482-013-9911-7.

34. Aftab U, Zechel DL, Sajid I. Antitumor compounds from Streptomyces sp. KML-2, isolated from Khewra salt mines, Pakistan. Biol Res. 2015. https://doi. org/10.1186/s40659-015-0046-3.
35. Kurapova I, Zenova GM, Sudnitsyn II, Kizilova AK, Manucharova NA, Norovsuren ZH, Zvyagintsev DG. Thermotolerant and thermophilic Actinomycetes from soils of Mongolia Desert steppe zone. Microbiology. 2012:81:98-108.

36. Okoro CK, Brown R, Jones AL, Andrews BA, Asenjo JA, Goodfellow M, Bull AT. Diversity of culturable actinomycetes in hyper arid soils of the Atacama Desert,Chile. Antonie van Leeuwenhoek. 2009;95:121-33.

37. Nithya K, Muthukumar C, Duraipandiyan V, Dhanasekaran D, Thajuddin N. Diversity and antimicrobial potential of culturable actinobacteria from desert soils of Saudi Arabia. J Pharm Sci Res. 2015;7:117-22.

38. Taddei A, Valderrama M, Giarrizzo J, Rey M, Castelli C. Chemical screening: a simple approach to visualizing Streptomyces diversity for drug discovery and further research. Res Microbiol. 2006;157:291-7.
Ready to submit your research? Choose BMC and benefit from:

- fast, convenient online submission

- thorough peer review by experienced researchers in your field

- rapid publication on acceptance

- support for research data, including large and complex data types

- gold Open Access which fosters wider collaboration and increased citations

- maximum visibility for your research: over $100 \mathrm{M}$ website views per year

At BMC, research is always in progress.

Learn more biomedcentral.com/submissions 